\title{
Glycosaminoglycans: Sweet as Sugar Targets for Topical Skin Anti-Aging
}

\section{Siew Tein Wang (ID \\ Boon Hoe Neo (D) \\ Richard J Betts (D)}

L'Oréal Research \& Innovation, L'Oréal Singapore, Singapore
Correspondence: Richard J Betts

Email richard.betts@rd.loreal.com

\begin{abstract}
Glycosaminoglycans (GAGs) are long, linear polysaccharides comprised of repeating disaccharide units with pleiotropic biological functions, with the non-sulfated GAG hyaluronic acid (HA), and sulfated GAGs dermatan sulfate, chondroitin sulfate, heparan sulfate, keratan sulfate, and to a lesser extent heparin all being expressed in skin. Their ability to regulate keratinocyte proliferation and differentiation, inflammatory processes and extracellular matrix composition and quality demonstrates their critical role in regulating skin physiology. Similarly, the water-binding properties of GAGs and structural qualities, particularly for HA, are crucial for maintaining proper skin form and hydration. The biological importance of GAGs, as well as extensive evidence that their properties and functions are altered in both chronological and extrinsic skin aging, makes them highly promising targets to improve cosmetic skin quality. Within the present review, we examine the cutaneous biological activity of GAGs alongside the protein complexes they form called proteoglycans and summarize the age-related changes of these molecules in skin. We also examine current topical interventional approaches to modulate GAGs for improved skin quality such as direct exogenous administration of GAGs, with a particular interest in strategies targeted at potentiating GAG levels in skin through either attenuating GAG degradation or increasing GAG production.
\end{abstract}

Keywords: proteoglycan, growth factor, retinoic acid, hyaluronic acid, C-xyloside

\section{Introduction}

Significant advances within the field of aesthetic medicine have been made over the past 20 years, with effective treatments such as Botox, skin peels and laser treatments offering readily perceived efficacy against age-associated decline in skin quality. While medical approaches have proved successful, these are generally not the first resort for consumers. Imparting high levels of efficacy for more accessible cosmetic approaches for anti-aging, especially those focused around small molecules or natural extracts, is not without challenges. A key issue for successful molecule/extract screening and development is to select the most appropriate biological targets, with strategies aimed at pathways exhibiting important biological activity and/or differential regulation through the aging process most likely to offer clinically perceivable benefits.

Glycosaminoglycans are a well-recognized skincare target due to their high endogenous expression in skin, pleiotropic biological action and attenuated expression/activity within aged skin. The unsulfated GAG hyaluronic acid (HA) features particularly prominently within skincare, however sulfated GAGs such as chondroitin sulfate (CS), dermatan sulfate (DS), heparan sulfate (HS), and keratan 
sulfate (KS) also possess strong biological activity that can be modulated to improve skin quality. Within the present review we aim to examine the scientific territory concerning GAGs in skin, as well as their associated proteoglycans. We examine current raw material approaches aimed at leveraging GAGs to improve skin quality, with particular interest in strategies concerning sulfated GAGs and increasing endogenous GAG production within skin.

\section{Glycosaminoglycans}

Glycosaminoglycans are long, linear polysaccharides comprised of repeating disaccharide units and are ubiquitous within the skin, being present intracellularly, on the cell surface and within the extracellular matrix (ECM). ${ }^{1}$ There are six key types of GAGs; (1) CS, (2) DS, (3) HS, (4) heparin, (5) KS, and (6) hyaluronic acid (HA). ${ }^{2}$ Hyaluronic acid is an atypical GAG, unique by virtue of being non-sulfated, of large molecular size, and undergoing molecular assembly at the cytoplasm rather than the Golgi apparatus. All others are collectively referred to as sulfated GAGs.

Sulfated GAGs are synthesized in the rough endoplasmic reticulum on which a serine amino acid (asparagine or threonine possible for $\mathrm{KS}$ ) of the core protein is attached with a xylose residue, followed by two galactose residues and a single glucuronic acid molecule. This four molecule group is known as the tetrasaccharide linker and constitutes the stem oligosaccharide structure common to all sulfated GAGs except KS, on which repeating disaccharide units are added to form different GAG types. ${ }^{3}$ These units are comprised of uronic acid family members glucuronic acid or iduronic acid, or the monosaccharide galactose for KS molecules, and a unit of an amino sugar (either N-acetylglucosamine (GlcNAc), N-acetylgalactosamine (GalNAc) or glucosamine $(\mathrm{GlcN})$ ), with the GAG chains reaching up to 100 repeating units in length for $\mathrm{KS}, \mathrm{CS}$, and DS, or up to 200 for $\mathrm{HS}^{4,5}$ (Figure 1A; Table 1). Posttranslational modification of sulfated GAG by both epimerization and sulfation follows characteristic patterns but creates a high degree of structural GAG variation and complexity of GAG biological activity.

Within skin, CS, DS, KS, and HS are of particular importance. Chondroitin sulfate and DS are generally considered to be of the same family, with CS composed of repeated disaccharide units consisting of GalNAc and glucuronic acid. The glucuronic acid residues can be further epimerized to iduronic acid, with the resulting structure being DS. ${ }^{6}$ Chondroitin sulfate and DS chains can be sulfated at the 4-O position on GalNAc (known as C4S for CS), however CS can also be sulfated at 6-O (C6S), or unsulfated. A chain will frequently contain both patterns of sulfation, while oversulfated forms of CS also exist where GalNAc is sulfated at both 4-O and 6-O positions. ${ }^{3}$ The iduronic acid of DS can also be sulfated at the 2-O position. This heterogeneity is referred to as alterations in the "fine structure" of GAGs. ${ }^{7}$ These minor fine structure differences result in GAGs with overlapping but slightly different biological profiles, driving heterogeneity of GAG function. ${ }^{8,9}$ Heparan sulfate, and the structurally related heparin, are synthesized as repeating units of GlcNAc and glucuronic acid. Disaccharide blocks along the GAG chain are then N-deacetylated and $\mathrm{N}$-sulfated via glucosaminyl N-deacetylase/N-sulfotransferase (NDST), which removes acetyl groups from GlcNAc and then sulfates the N-position of GlcN residues. Further potential modifcation steps include C5 epimerization of glucuronic acid to iduronic acid, 2-O sulfation of iduronic acid, and 6-O or (rarely) 3-O sulfation of GlcN units. ${ }^{4}$ The complexities of HS biosynthesis have been comprehensively reviewed by Kreuger \& Kjellén. ${ }^{15}$ Heparin is more structurally homogeneous than HS, exhibiting a greater degree of sulfation and higher content of iduronic acid than HS, but is restricted to expression in mast cells. ${ }^{11}$ Keratan sulfate exists in two forms, KS-I and KS-II, with KS-I being found in skin. ${ }^{12}$ They differ on the basis of their linkage to their core protein, with both possessing repeating units of galactose and GlcNAc with either sugar able to be sulfated at the 6-O position. ${ }^{3}$

While the biochemical processes and enzymes responsible for GAG synthesis are well known, the exact processes that regulate heterogeneity of GAG structure are still poorly understood. Current hypotheses focus on the cell altering relative expression levels of modifying enzymes to regulate structure, and that these enzymes may act together in physical complexes, a model dubbed the "GAGosome". 13,14 The variations of GAG length, post-modification patterns, GAG chain differential sulfation sites, and the formation of specific binding motifs creates complex biological signaling networks that modulate cytokines and growth factors, as well as cell/matrix interaction proteins including various collagens. ${ }^{1,14}$

The end products of the synthesis process are complexes of GAGs attached to a protein core, known as the proteoglycan unit, which are present in virtually all mammalian cells either secreted outside the cell, inserted into the plasma membrane or stored within secretory 
A

Hyaluronidase Hyaluronic acid-binding proteoglycans

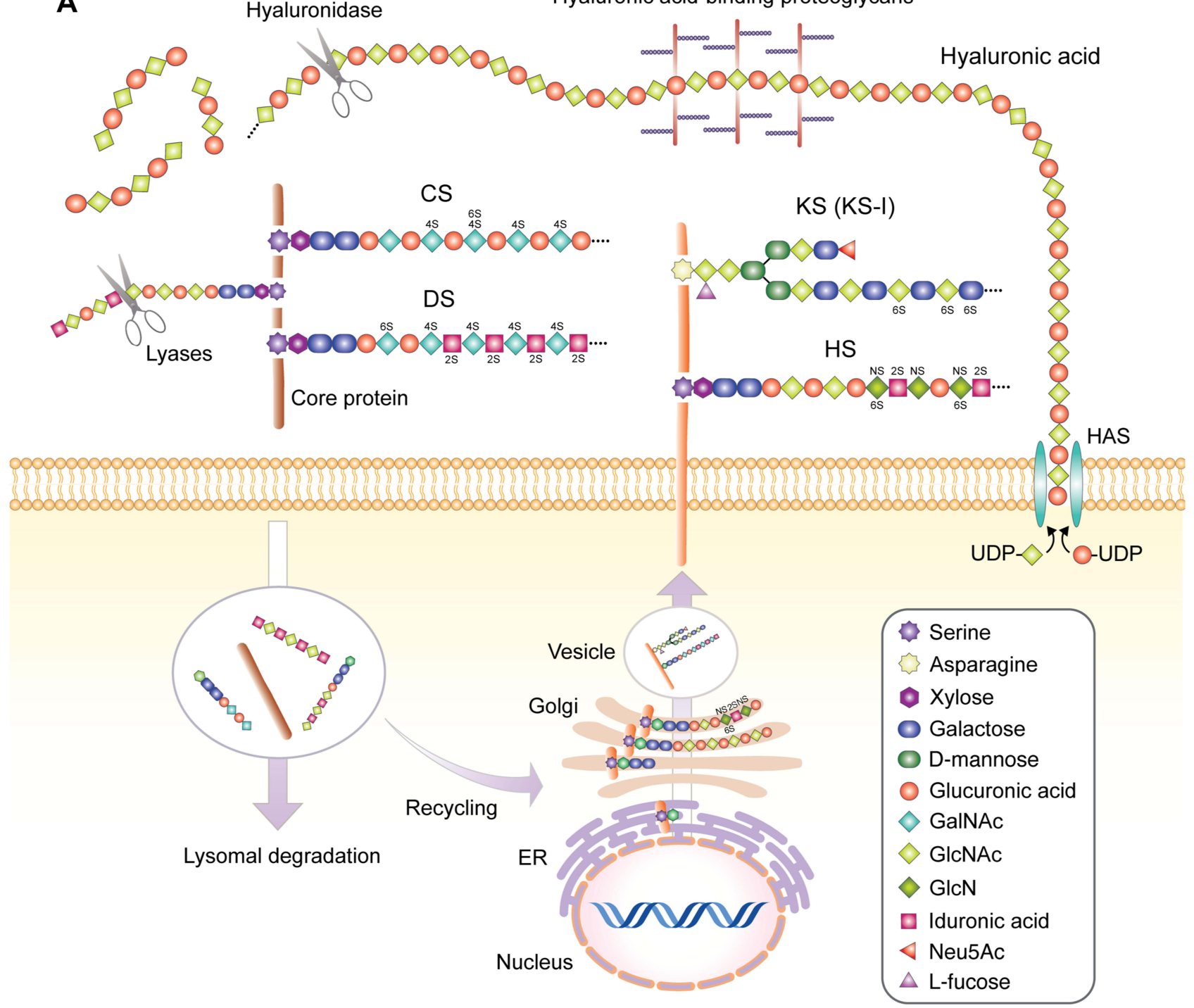

B
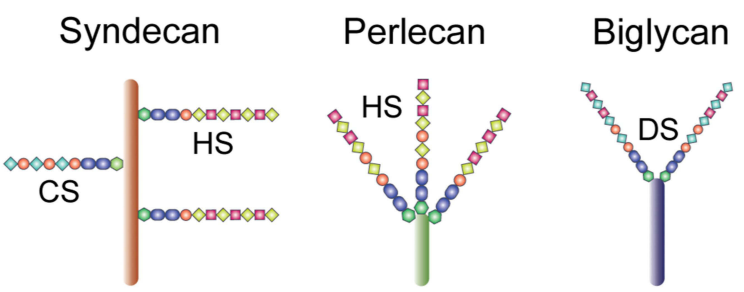

Versican

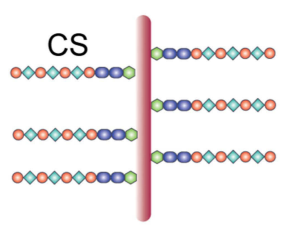

Lumican

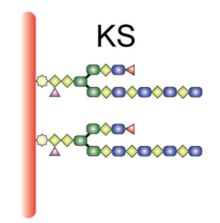

Decorin

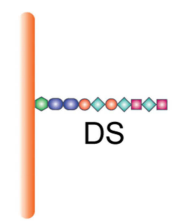

Figure I (A) Structure of GAGs found in skin and synthesis processes. Key skin sulfated GAGs heparan sulfate (HS), dermatan sulfate (DS), chondroitin sulfate (CS) and keratin sulfate (KS, KS-I form depicted) are synthesized on a protein backbone with the xylose group attached in the endoplasmic reticulum (ER), followed by the sugar groups added in the Golgi apparatus, sulfation at the trans-Golgi and finally transportation to the plasma membrane via vesicles to form transmembrane units or excreted into the extracellular space, or more rarely located intracellularly (not depicted). The sulfated GAGs covalently bound to the core protein backbone create a proteoglycan unit, with differences in core proteins, the type of GAG bound to the protein, variations in the GAG sulfation sites and number of attached GAGs resulting in different proteoglycan families and considerable within-family diversity. These GAG chains can be degraded by lyases such as heparinase or chondroitinase, while the proteoglycan unit is subject to lysosomal degradation and intracellular recycling. Hyaluronic acid is synthesized by membrane-associated HAS enzymes, resulting in long HA chains which do not bind to a protein core, but can bind other proteoglycan complexes, which can be degraded by hyaluronidase. $2 \mathrm{~S}, 4 \mathrm{~S}$, and $6 \mathrm{~S}$ represent sulfation at 2-O, 4-O \& 6-O positions, respectively. NS represents N-sulfated (B) proteoglycans that feature prominently in skin and their commonly associated GAG formations. Sizes not to scale. 
Table I Glycoaminoglycan Repeating Disaccharide Units and Common Skin Proteoglycan Composition

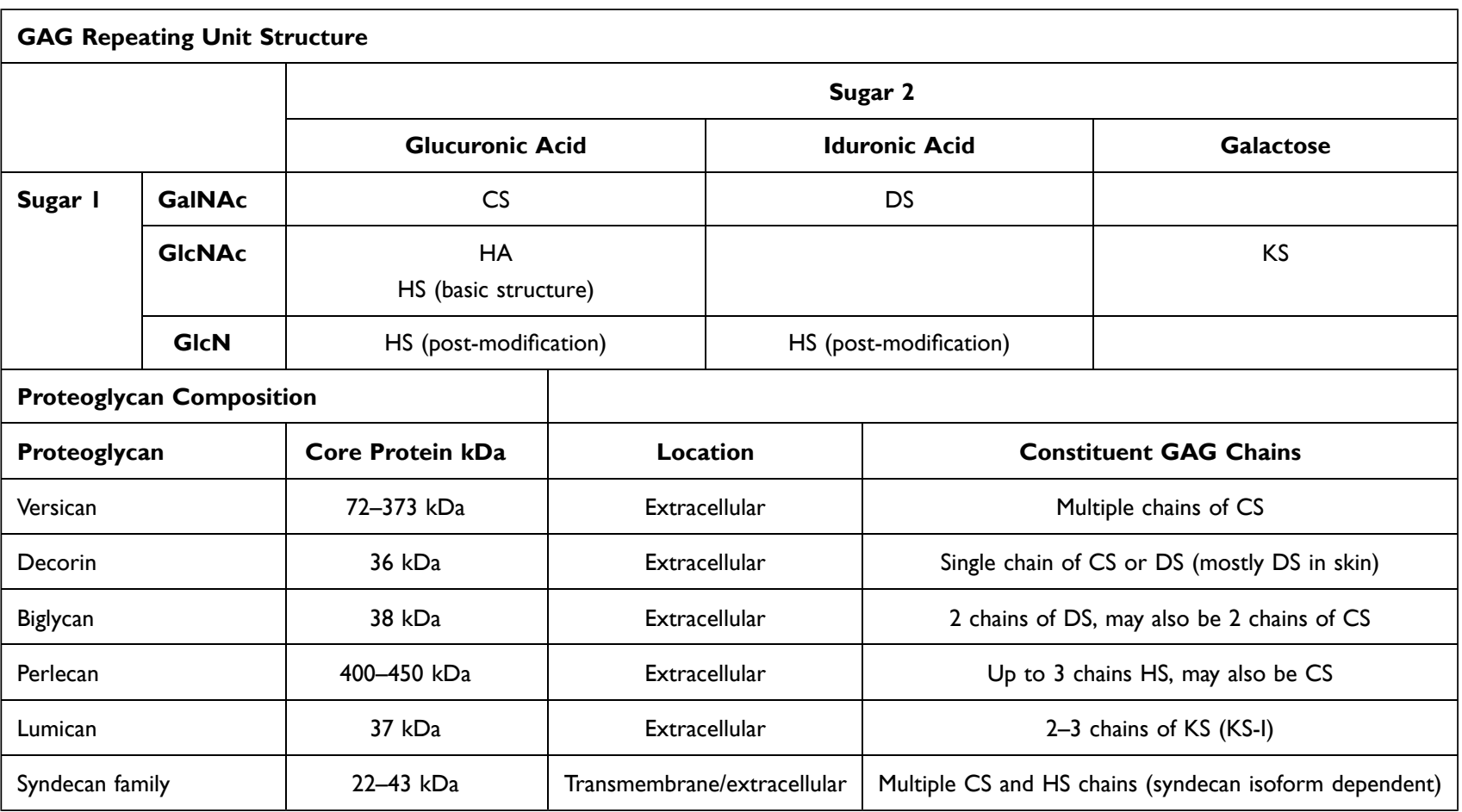

Notes: Glycosaminoglycan repeating units are composed of an amino sugar (sugar I), and a uronic sugar (sugar 2). The exception is KS, which has the monosaccharide sugar galactose in place of an uronic sugar. Heparan sulfate is initially comprised of GlcNAc \& glucuronic acid repeating units, with $\mathrm{N}$-acetylation/ $\mathrm{N}$-sulfation of GlcNAc yielding sections of $\mathrm{N}$-sulfated $\mathrm{GlcN}$ which can subsequently be 6-O sulfated, or rarely 3-O sulfated. Some glucuronic acid groups are transformed to iduronic acid, likely determined by different proportions of sulfotransferases \& epimerases. Proteoglycans consist of a protein backbone with characteristic constituent GAG chains, and may contain single or multiple GAG chains. Characteristics of prominent proteoglycans in skin shown ${ }^{3}$.

granules. $^{12}$ The GAG chains of extracellular and membrane-associated proteoglycans can be degraded by endosulfatases or extracellular lysases such as heparinase and chondroitinase acting on their respective GAGs, and are also internalized for lysosomal degradation or recycling, whereby the protein core can have its GAG chains trimmed or altered and re-exported to the cell membrane. ${ }^{15}$ Proteoglycans are extremely diverse and are critical in a large array of biological activities, so while soluble GAG chains not in proteoglycan complexes are also capable of exerting powerful biological effects, ${ }^{13,16}$ much of the research concerning the physiological function of sulfated GAGs in skin is conducted in the context of proteoglycan interactions.

Hyaluronic acid is synthesized at the cytoplasm by three HA synthases (HAS 1-3). Cytosolic substrates UDPGlucuronic acid and UDP-GlcNAc are added to the reducing end of the polymer by HAS, resulting in the release of UDP and the synthesis of repeating polymeric disaccharides of glucuronic acid and GlcNAc linked via a glucuronidic $\beta(1 \rightarrow 3)$ bond (Figure $1 \mathrm{~B}) .{ }^{17}$ Hyaluronic acid synthase 1 and HAS2 yielded larger size HA ranging from $2-4 \times 10^{6}$ Da HA, while the HAS3 HA product typically ranges between $0.4-2.5 \times 10^{5} \mathrm{Da}$, with HAS2 predominating within skin. ${ }^{18}$ Following synthesis, HA molecules are directly excreted into the extracellular space, where they can act on their cognate receptors CD44 and Receptor for HA-Mediated Mobility (RHAMM). ${ }^{18,19}$ Hyaluronic acid is physiologically important for both its mechanical and biological properties. The unique helical coil conformation of HA allows it to trap up to 1000 -fold of its weight in water, making HA critical for maintaining tissue structure and volume, while crosslinking of HA to proteoglycans provides stability to the ECM. ${ }^{18}$ Ligation of CD44 or RHAMM by HA also activates cell proliferation, migration and differentiation, significantly modulating biological pathways within the skin. ${ }^{18}$

\section{Proteoglycans}

Proteoglycans are found within the cell membrane, the ECM, and located within intracellular compartments. Cell surface proteoglycans either span the plasma membrane or are linked via a membrane-associated anchor, 
those in the ECM mostly secreted but in some cases proteolytically cleaved and shed from the cell membrane. ${ }^{12}$ The main core protein holds sulfated GAGs chains attached via various glycosyltransferases and sulfotransferases, and can be a single type of GAG or multiple types depending on the proteoglycan. ${ }^{7,20}$ Biglycan, versican lumican and decorin are abundant in skin and feature mostly exclusive associations with their corresponding GAG type, ${ }^{21-23}$ while syndecans, a key family of membrane-bound proteoglycan in the skin, are capable of binding $\mathrm{HS}$ and $\mathrm{CS}$, and perlecan, an extracellular matrix proteoglycan, predominately exhibits chains of HS but is also capable of mixed $\mathrm{HS} / \mathrm{CS}$ possession. ${ }^{24,25}$ Proteoglycans may also differ in the number of GAG chains they can carry, with biglycan typically holding two chains of either CS or DS (with DS being more common), while aggrecan can hold in excess of 100 chains. ${ }^{12}$ Further distinction can be made on the basis of core protein size, with the small leucine-rich proteoglycan (SLRP) family of ECM-associated proteoglycans such as decorin, lumican and biglycan exhibiting protein cores of 40-60 kDa with 10-12 leucine-rich repeat motifs, and are highly important in skin. This GAG variability and stoichiometric variation creates a confluence of factors leading to an extremely high degree of variation within GAGproteoglycan association.

Proteoglycan production is governed by an extraordinary complex set of processes encompassing transcription factors, glycosyltransferases and sugar nucleotide transporters, many of which remain poorly understood. The most prominent upstream effectors of proteoglycan production are growth factors and cytokines, which can induce differential regulation of proteoglycans in tissue-specific and dose-dependent ways. Interleukin-1 $\beta$, for example, decreases versican synthesis in skin fibroblasts, but upregulates it in lung fibroblasts, ${ }^{26,27}$ while IFN- $\alpha$, IFN- $\beta$, IFN- $\gamma$, TGF- $\alpha$, TGF- $\beta$, IL- 2 and GMCSF all exhibit differential dose-dependent effects on total GAG induction within human dermal fibroblasts. ${ }^{28,29}$ Fibroblast growth factor (FGF) family members are particularly prominent regulators of proteoglycan expression, especially for SLRP family members. ${ }^{30}$ Within dermal fibroblasts, FGF-2 decreases biglycan synthesis while increasing decorin, ${ }^{31}$ and FGF family members are particularly important regulators of syndecans via FGF-inducible response elements. $^{32,33}$ The large numbers of cytokines and growth factors that differentially regulate production of any given proteoglycan suggests that concentration gradients across different permutations of growth factors are critical in governing proteoglycan synthesis and composition.

\section{Glycosaminoglycan/Proteoglycan Physiological Role Within Skin}

Glycosaminoglycans make up $0.1-0.3 \%$ of total skin weight, with $\sim 6-7$-fold more GAG present in the dermis compared with epidermis. ${ }^{34}$ While exact numbers range between studies and the skin site examined, HA comprises approximately half of all GAG within total skin from young donors, with sulfated GAG bound in proteoglycan complexes constituting the other half. Of the sulfated GAGs, CS/DS predominates with an overall trend to slightly higher levels of DS, while there are much lower levels of $\mathrm{HS}$ and $\mathrm{KS}^{35,36}$ These estimates are consistent with GAG proportions in the dermis, however within the epidermis there are relatively high levels of $\mathrm{C} 4 \mathrm{~S}$, HS and low levels of $\mathrm{KS}$ expressed, while the basal epidermis is the only site containing $\mathrm{C} 6 \mathrm{~S} .{ }^{37}$ Hyaluronic acid within the epidermis is mostly extracellular and located at the upper spinous and granular epidermal layers, although there is some intracellular HA located in the basal layer. ${ }^{17}$

Hyaluronic acid forms an important structural component of the ECM, acting as a scaffold for macroproteins which decorate the HA chains in a bottlebrush formation, with ECM areas containing thinner fibers showing highest levels of HA deposition. ${ }^{17}$ HA can similarly bind proteoglycans such as aggrecan, facilitating the biological functions of extracellular proteoglycans. ${ }^{38}$ The high amounts of water bound by HA are critical for maintaining adequate hydration within the skin, promoting both physiological function of the skin and the maintenance of cosmetic skin quality. The signaling properties of HA within the skin, as in other tissues, is to a large degree a function of the molecule size. High-molecular weight HA (HMW-HA) suppresses inflammation and angiogenesis, while low-molecular weight HA (LMW-HA) created from the cleavage of HA within the site of injury can promote inflammation and scar formation, and increase angiogenesis. ${ }^{39,40}$ Low-molecular weight HA however is able to function as an antioxidant scavenger, and promotes wound healing through ROS quenching. ${ }^{41,42} \mathrm{HA}$ is able to facilitate the movement of Langerhans cells through the epidermis by binding CD44 found on the surface of these cells, and therefore may help promote immune homeostasis given the well-known immune tolerance functions of Langerhans cells. ${ }^{43}$ Ligation of keratinocyte-associated CD44 by $\mathrm{HA}$ is 
reported to promote epidermal differentiation and increase barrier function, ${ }^{44}$ although the precise role for HA in epidermal differentiation remains controversial with suggestions that only with very low or high HA levels (e.g. as imparted by exogenous HA administration) is epidermal differentiation increased. ${ }^{45}$ The binding of HA to CD44 is also influenced by molecule size, with large HA $(\sim 30 \mathrm{kDa})$ possibly binding with increased affinity and irreversibly compared to smaller $<10 \mathrm{kDa}$ HA molecules. ${ }^{46}$

While mRNA for most of the 43 genes encoding proteoglycans is found within the skin, protein is only expressed for a handful of them. ${ }^{47}$ The ECM of the dermis is particularly rich in SLRPs where they have two core biological functions: (1) regulating collagen fibril production, organization and ECM assembly, and (2) to modulate the bioactivities of endogenous chemokines, cytokines, ligands and receptors which are instrumental to the wound healing process. ${ }^{48}$ Of the SLRP family, decorin is the most common in skin and is the main proteoglycan that binds collagen fibrils together within the dermis to form stable collagen fibers. ${ }^{49}$ The importance of decorin is underscored by the rare genetic connective tissue disorder Ehlers-Danlos syndrome (EDS), which presents as loose and painful joints, excessive skin elasticity and abnormal scar formation. The CHST14 form of EDS results in dermatan 4-O-sulfotransferase deficiency and therefore a complete loss of DS-decorin complexes, with DS being replaced by CS. ${ }^{50,51}$ Mice lacking the Chst 14 gene possess very low levels of cutaneous DS, resulting in disorganized collagen bundles and reduced skin tensile strength. ${ }^{52}$ Biglycan is expressed at relatively low levels within the dermis ${ }^{53}$ but nevertheless interacts with Type I collagen fibers and when deleted within mouse knockout models results in collagen fibril abnormalities and skin fragility. ${ }^{21,54}$ Lumican, which primarily expresses the KS-I isoform of KS, is highly expressed in skin and similarly regulates fibril assembly and promotes wound healing by facilitating fibroblast activation and contraction. ${ }^{55}$

Versican, an extracellular proteoglycan of the hyalectin family, is widely detected in both epidermis and dermis, where it promotes proliferation ${ }^{56}$ and facilitates the fibroblast-myofibroblast transition within the dermis through inhibition of a versican-degrading protease, assisting in skin wound healing. ${ }^{57}$ Perlecan is a particularly important extracellular proteoglycan of the DEJ, where it interacts with a broad array of molecules including growth factors and key basement membrane constituents laminin 111 and
511, collagen IV and $\beta 1$-integrins. ${ }^{58}$ Reconstruction of organotypic skin with perlecan-deficient keratinocytes results in thin and poorly organized epidermis, highlighting its importance in maintaining epidermal homeostasis. ${ }^{59}$ Syndecan-1 and -4 are abundantly expressed in skin, ${ }^{60}$ and mice null for syndecan-1 exhibit defects in keratinocyte migration, while deletion of the gene encoding syndecan-4 results in delayed wound repair and deficits in angiogenesis. ${ }^{61,62}$ Syndecans play a critical physiological role through binding cytokines/chemokines on their attached HS or CS chains, helping to facilitate the presentation of these factors to their cognate receptors, and assist in the endocytosis of external factors. ${ }^{63}$ The critical role for GAGs \& proteoglycan within the homeostatic skin and for wound-healing responses hints at their potential for modulation to improve cosmetic skin quality. A summary of key mechanisms for $\mathrm{GAG} /$ proteoglycan regulation of skin is found in Figure 2.

\section{Glycosaminoglycans/Proteoglycans in Skin Aging}

The biological phenomenon of skin aging can be divided into two major categories, intrinsic and extrinsic aging, based on their causes and observed clinical signs. Intrinsic aging results from internal physiological factors that are largely inescapable consequences of the passage of time and manifests as fine lines, thinned epidermis, and gradual dermal atrophy. Extrinsic aging is the sum of all external aggressors such as UV light, pollution and cigarette smoke exposure that results in coarse wrinkles, loss of elasticity and rough texture. ${ }^{19,64,65}$

Total sulfated GAG levels are reduced within intrinsically aged skin compared with young samples. ${ }^{66}$ Furthermore the relative proportions of GAG are also altered, with intrinsically aged skin samples demonstrating decreases in HS and CS levels, particularly C6S in the basal lamina, while conversely KS and DS are increased. ${ }^{19,65}$ Expression of CS is higher in fetal skin when compared to mature skin, which may contribute to the scarless healing ability of fetal skin. ${ }^{67}$ In contrast to intrinsically aged skin, photoaged skin shows an increase in total sulfated GAG levels within males, consistent with data showing elevated dermal CS in a cohort of volunteers subjected to either short- or medium-term UV exposure. ${ }^{68}$ Beyond GAG levels found within skin, the pattern of GAG deposition is also critical. The GAGs within sun-damaged skin are deposited on the elastotic material of the papillary 


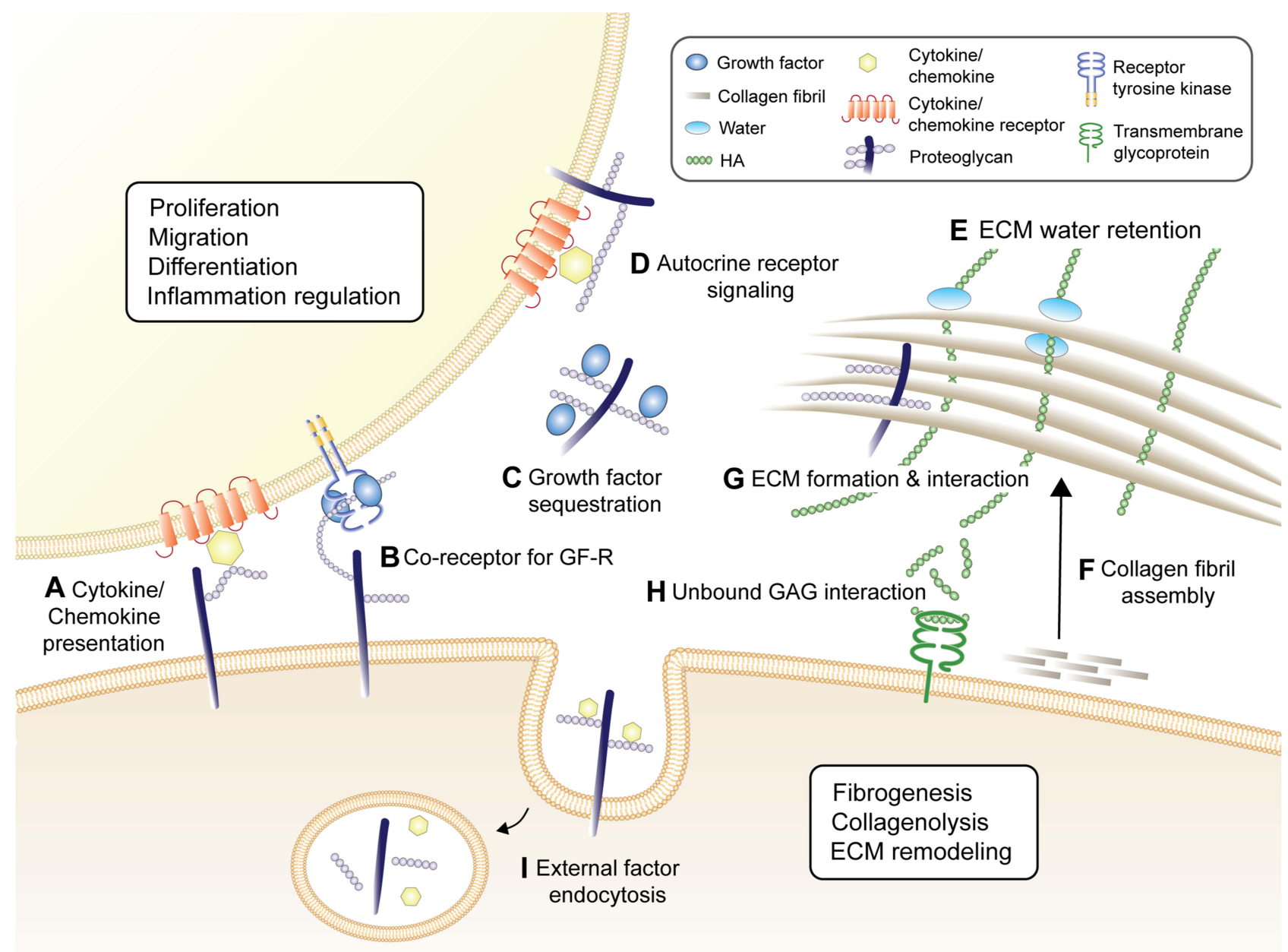

Figure 2 Key biological activities of GAG \& proteoglycans in skin. (A) Proteoglycans act to present chemokines/cytokines to their cognate receptors. (B) GAG chains on proteoglycan act as co-receptors for growth factor receptors (GF-R), potentiating GF-R signaling. (C) They can also sequester growth factors, protecting them from proteinase activity and thermal instability which can then be later released to activate GF-R, and (D) potentiate autocrine receptor signaling and clustering. These pathways result in proteoglycans holding important roles in skin cell proliferation, migration, differentiation and inflammatory signaling, all of which critical for skin homeostasis and wound repair. Proteoglycans and HA are critical for the formation and structural stability of the ECM, and are particularly important in (E) ECM water retention, ensuring adequate cutaneous hydration, (F) collagen fibril assembly, and (G) ECM formation and structural stability. Soluble GAGs, particularly HA, are capable of directly interacting with the membrane-bound receptors, shown here as HA interacting with CD44 that plays a critical role in dermal fibrogenesis, regulating collagenolysis and ECM remodeling (H). (I) Proteoglycan endocytose external factors such as cytokines and chemokines, making them available intracellularly or transporting them across the cell membrane for degradation.

dermis as opposed to between collagen and elastin fibers of normal skin, ${ }^{69}$ which may suggest attenuated collagen fibril organization functions for GAG within photoexposed skin.

Hyaluronic acid is reduced in adult skin compared with juvenile skin, alongside downregulation of CD44, HAS1, HAS2 and RHAMM. ${ }^{70}$ Within photoaged skin there are similarly decreased levels of HAS1, CD44 and RHAMM, but also an increase of low mass HA. ${ }^{71}$ The observed changes are mirrored by in vitro studies on human fibroblasts, which also demonstrate attenuation of HAS2 mRNA by UVB exposure, a process mediated by collagen fragments. $^{72}$ While the exact contribution of changes in HA to the aged skin phenotype remains under question, the dysregulation of HA homeostasis in both intrinsic and extrinsic aging is clear.

Among proteoglycans, perlecan expression within the skin is reduced during physiological aging, and aged keratinocytes exhibit dramatically reduced perlecan mRNA transcripts. ${ }^{73}$ Interestingly, the same study demonstrated that addition of exogenous perlecan to the culture media of 3D organotypic skin reconstructed with aged keratinocytes results in epidermal thickening, suggesting perlecan to be a potential target for anti-aging intervention. 
Absolute proteoglycan levels need not change within aging for their function to be altered or attenuated. $\mathrm{Li}$ and colleagues found that decorin levels within aged skin remain constant, but decorin from aged donors displays shorter GAG chains compared with those from younger skin, possibly contributing to skin fragility. ${ }^{53}$ Decorin levels are reduced in photoaged skin however, with fibroblasts isolated from photodamaged sites producing $46 \%$ less mRNA under basal conditions. ${ }^{69}$

The complexity of GAG and proteoglycan chemistry and differential changes during aging underscores the importance of not only examining changes in absolute levels of these factors, but also their altered structures, functional abilities and localization within the skin. The broad distribution and critical role of GAG and proteoglycans within skin suggests they are likely major players within skin aging, and therefore represent a promising target for anti-aging intervention. A comprehensive list of changes of GAG and proteoglycans within intrinsic and extrinsic aging is given in Table 2 .

\section{Proteoglycan Regulation of Growth Factor Activity}

Growth factors encompass a broad family of proteins that can act in autocrine, paracrine or endocrine manner to stimulate cell migration, proliferation and differentiation. ${ }^{74}$ While there are many growth factor families as determined on the basis of structure, receptor specificities and functional properties, the Fibroblast Growth Factor (FGF) family, Epidermal Growth Factor (EGF) family, transforming growth factor-beta (TGFß) superfamily, platelet-derived growth factor (PDGF) family, and vascular endothelial growth factor (VEGF) family are all particularly important within skin due to their roles within skin homeostasis and wound healing. ${ }^{75}$

The powerful ability of growth factors to promote reepithelialization, angiogenesis, fibroblast proliferation and survival has created interest in their activity to improve the cosmetic quality of chronologically and photo-aged skin. ${ }^{76}$ The FGF family, consisting of 22 different molecules divided into 7 discrete subfamilies, as well as EGF are of potential interest due to their mitogenic and motogenic properties ${ }^{77}$ and are the basis for the majority of growth factor-associated anti-aging approaches. Within the FGF family, acidic FGF (aFGF/FGF1) and basic FGF (bFGF/FGF2) have been of particular cosmetic interest and feature in a large number of cosmetic products that claim an anti-aging effect. ${ }^{77}$ Keratinocyte Growth Factor (KGF/FGF7) acts to induce epidermal thickening and therefore may also be particularly beneficial for epidermis-related endpoints. ${ }^{78}$

While there is evidence of growth factor efficacy on skin quality, especially when combined with enhanced delivery systems such as microneedles or protein encapsulation to improve bioavailability, ${ }^{79-81}$ the effectiveness of growth factor topical administration is constrained due to their large size and susceptibility to proteinases. Other approaches such as increasing the stabilization of endogenous growth factors offer the potential to circumvent these issues, acting to increase growth factors levels within the skin without directly increasing growth factor production though sequestration in a stable conformation, resulting in enhanced biological activity. ${ }^{82-84}$ This is particularly the case with many FGF family molecules, which demonstrate a high degree of thermal instability that attenuates their signaling ability. ${ }^{85}$

Extracellular-matrix proteoglycans and GAG fragments (particularly of $\mathrm{HS}^{86,87}$ ) are critical for regulating growth factor pathways and stabilize growth factors within the skin through protection from degradation, and also increase the affinity of growth factor for its cognate receptor and stabilize the receptor-ligand complex. ${ }^{88}$ Heparan sulfate proteoglycans in the skin act to bind and regulate growth factors through syndecans at the cell surface, or via perlecans at the basement membrane of the DEJ. ${ }^{74,89,90}$ Hyaluronic acid similarly binds TGF- $\beta$, protecting it from tryptic degradation and therefore modulating TGF- $\beta$ bioavailability. ${ }^{91}$ After their liberation from ECM-associated sequestration, FGF ligands bind to their cognate receptor in a HS-proteoglycan-dependent manner. ${ }^{75}$ Fibroblast Growth Factors are dependent on HSproteoglycan signaling in vivo via bridging between the contact receptor and ligand, cross-linking and stabilizing the complex via the 6-O-sulfate group on the HS/heparin GlcN. ${ }^{92,93}$ Consequently, disruption of HS-proteoglycan function causes a loss of FGF signal transduction and greatly attenuated cell migration. ${ }^{94}$ The multifaceted mechanisms through which GAG, and HS-proteoglycans in particular, act to stabilize growth factors and facilitate their biological activity demonstrate that cosmetic interventions that increase cutaneous GAG content may also act to potentiate the endogenous growth factor effect.

\section{Cosmetic Approaches for Anti-Aging GAG/ Proteoglycan Modulation}

Topical strategies for targeting GAGs can broadly fall into two categories; direct addition of GAGs into topical 
Table 2 Changing During Intrinsic and Extrinsic Aging of GAG and Proteoglycans Commonly Found in Skin

\begin{tabular}{|c|c|c|c|}
\hline & Skin Layer & Intrinsic Aging Modulation & Extrinsic Aging Modulation \\
\hline \multicolumn{4}{|c|}{ HA and related molecules } \\
\hline \multirow[t]{2}{*}{$\mathrm{HA}$} & Epidermis & $\downarrow^{66} \mathrm{NC}^{141}$ & $\begin{array}{c}\text { 个total skin: low mass } \mathrm{HA},{ }^{71} \uparrow U V B \text {-induced at basal } \\
\text { layer only }{ }^{68}\end{array}$ \\
\hline & Dermis & $\downarrow,^{66} \downarrow$ (female), ${ }^{68} \mathrm{NC}^{141}$ & $\uparrow^{36}$ \\
\hline \multirow[t]{2}{*}{ HAS } & Epidermis & $\downarrow$ HAS2, ${ }^{66} \downarrow$ HASI $\uparrow H A S 3$ mRNA total skin ${ }^{70}$ & \multirow[t]{2}{*}{$\downarrow$ HASI total $\mathrm{skin}^{71}$} \\
\hline & Dermis & $\downarrow H A S 2^{66}$ & \\
\hline \multirow[t]{2}{*}{ CD44 } & Epidermis & $\downarrow^{66}$ & \multirow[t]{2}{*}{$\downarrow$ Total skin ${ }^{71}$} \\
\hline & Dermis & $\downarrow^{66}$ & \\
\hline \multirow[t]{2}{*}{ RHAMM } & Epidermis & \multirow[t]{2}{*}{$\downarrow$ Total skin mRNA ${ }^{70}$} & \multirow[t]{2}{*}{$\downarrow$ Total skin ${ }^{71}$} \\
\hline & Dermis & & \\
\hline \multicolumn{4}{|c|}{ Sulfated GAGs } \\
\hline \multirow{2}{*}{$\begin{array}{l}\text { Total Sulfated } \\
\text { GAG }\end{array}$} & Epidermis & $\downarrow^{66} \downarrow(\text { female })^{66}$ & $\uparrow,{ }^{141} \downarrow$ male only, ${ }^{66} \mathrm{NC}$ total $\mathrm{GAG}^{71}$ \\
\hline & Dermis & $\downarrow^{66}$ & $\uparrow,{ }^{141} \uparrow$ Total GAG, ${ }^{68} \mathrm{NC}^{66}$ \\
\hline \multirow[t]{2}{*}{ CS } & Epidermis & $\downarrow(\mathrm{C} 6 \mathrm{~S})^{37}$ & \\
\hline & Dermis & & NC total skin ${ }^{71}$ \\
\hline \multirow[t]{2}{*}{ DS } & Epidermis & $\uparrow^{37}$ & \\
\hline & Dermis & $\uparrow^{37}$ & NC, ${ }^{68} \uparrow$ whole skin ${ }^{71}$ \\
\hline \multirow[t]{2}{*}{ KS } & Epidermis & $\uparrow^{37}$ & \\
\hline & Dermis & & \\
\hline \multirow[t]{2}{*}{ HS } & Epidermis & $\downarrow^{66}$ & $\downarrow(D E J)^{142}$ \\
\hline & Dermis & $\downarrow^{66}$ & $\mathrm{LE},{ }^{142} \mathrm{NC}^{68}$ \\
\hline \multicolumn{4}{|c|}{ Proteoglycans } \\
\hline \multirow[t]{2}{*}{ Versican } & Epidermis & \multirow{2}{*}{$\begin{array}{l}\downarrow \text { total skin holding ability of GAG \& altered sulfation, }{ }^{23} \mathrm{NC} \\
\qquad \mathrm{mRNA},{ }^{143} \uparrow(\text { male })^{66}\end{array}$} & \\
\hline & Dermis & & $\uparrow(\mathrm{SE}),{ }^{69,143} \uparrow$ degraded protein ${ }^{144}$ \\
\hline \multirow[t]{2}{*}{ Decorin } & Epidermis & $\mathrm{LE}^{53}$ & \\
\hline & Dermis & $\downarrow^{66} \downarrow$ GAG holding ability ${ }^{53}$ & $\downarrow[\mathrm{SE}]^{69}$ \\
\hline \multirow[t]{2}{*}{ Biglycan } & Epidermis & $\downarrow$ total skin, ${ }^{19} \downarrow \mathrm{mRNA}^{70}$ & $\downarrow$ total $\operatorname{skin}^{19}$ \\
\hline & Dermis & NC aged fibroblasts ${ }^{145}$ & $\downarrow$ UV fibroblasts ${ }^{146}$ \\
\hline \multirow[t]{2}{*}{ Perlecan } & Epidermis & $\downarrow(\text { female })^{66}$ & $\uparrow$ acute $U V^{147}$ \\
\hline & Dermis & $\downarrow(\text { female })^{66}$ & $\uparrow$ acute $U V^{147}$ \\
\hline \multirow[t]{2}{*}{ Lumican } & Epidermis & & \\
\hline & Dermis & $\downarrow$ aged fibroblasts ${ }^{145}$ & \\
\hline \multirow[t]{2}{*}{ Syndecan } & Epidermis & $\downarrow$ Syndecan-I, NC Syndecan-46 $4^{66}$ & $\uparrow$ Syndecan-I/4 acute UV 147 \\
\hline & Dermis & Syndecan-I, NC Syndecan-466 & $\uparrow$ Syndecan-1/4 acute UV 147 \\
\hline
\end{tabular}

Notes: $\uparrow$ denotes increase; $\downarrow$ denotes decrease; NC denotes no change; LE denotes low expression, with the corresponding reference for the data; Blank means no data; Total skin denotes epidermis and dermis not separately analyzed; SE means data obtained in solar elastosis. 
formulations, or through more indirect means such as administration of molecules that potentiate the production or release of GAGs within the skin. Each approach possesses strengths and weaknesses; topical GAGs preparations act directly but face inherent issues of skin penetration and stability, while indirect approaches utilizing smaller molecules may have greater ability to penetrate past the stratum corneum, although a high degree of potency is required to significantly modulate GAG activity.

\section{Topical Application of GAGs}

Topical use of HA is a safe and effective mainstay of the cosmetics and aesthetics industry, with both topical formulations and injectable HA being popular (extensively reviewed by Bukhari and colleagues, ${ }^{95}$ including use of HA fillers beyond the scope of this review). Daily use of over-the-counter formulas containing high levels of HA results in clear reductions in wrinkle depth, skin laxity, skin dehydration with an increase in barrier function while displaying minimal adverse events, demonstrating HA to be an accessible and safe skincare solution. ${ }^{96-98}$ Large molecular weight HA will not penetrate the skin however, leading to the development of preparations containing HA fragments of varying sizes to improve skin penetration. Studies examining the degree of penetration past the stratum corneum of these HA molecules have produced conflicting results. Convincing data from Brown and coworkers using radiolabeled $\mathrm{HA}$ on hairless mice and a human volunteer suggested penetration past the stratum corneum, which the authors speculated to be the result of active transport. ${ }^{99}$ Conversely, Zhang and colleagues (2019) demonstrated minimal penetration of HA in pig skin without additional promoters of penetration such as spicules and liposomes. ${ }^{100}$ Despite these questions concerning skin penetration into the deeper layers of skin, penetration into the stratum corneum is plausible and may be consistent with clinical studies demonstrating efficacy for LMW-HA formulations.

Pavicic and co-workers utilized a $0.1 \%$ HA topical formulation containing HA ranging between 50-2000 $\mathrm{kDa}$, finding formulas with LMW-HA in particular were associated with a reduction in wrinkle depth. ${ }^{101}$ While these smaller HA fragments are still large molecules in the context of cutaneous bioavailability, biotinylated intermediate size (50-400 kDA) HA fragments were found in the dermis of hairless mice, consistent with some degree of skin penetration potentially via the hair follicle. Of particular note, intermediate size HA fragments mediated an increase in keratinocyte proliferation via a heparin bound-EGF and EGFR-activation-dependent mechanism in vitro, further implicating growth factor modulation in the positive biological activity of GAG in cosmetic skin quality.

Similar approaches have utilized HS fragments for topical use. Gallo and colleagues used a low molecular weight HS (LMW-HS)-containing formulation to reduce signs of facial aging on photodamaged skin, ${ }^{102}$ while a similar preparation reduced the appearance of hyperpigmentation and wrinkles when applied to the periorbital area. ${ }^{103}$ Colvan and colleagues similarly demonstrated that an eye cream containing LMW-HS and a blend of naturally derived extracts achieved skin rejuvenation by improving appearance of periorbital hyperpigmentation, puffiness, and fine and coarse wrinkles. ${ }^{104}$ Ito and colleagues (2017) examined fractions of Porcine Placental Extract (PPE), which has a long history of use for both cosmetic and medicinal purposes. They found the medium-to-high molecular weight fractions to be rich in heparin/HS and CS, which potentiated FGFR signaling and protected FGF1 growth factor from trypsin digestion in a similar way to control heparin. ${ }^{105}$ Low molecular weight fractions of PPE were also able to potentiate FGFR signaling and promote cell proliferation, perhaps suggesting these fractions contained bioactive GAG fragments. Such approaches clearly demonstrate the ability of GAGs to modulate growth factor signaling, and suggest that growth factor modulation may be a potential mechanism behind LMW-HS efficacy within skin.

Despite these promising data, skin penetration will likely remain a formulation challenge for topical penetration of exogenous GAG preparations. Hydrogels, nano/ microemulsions, liposomes and conjugation strategies have all been employed to increase the bioavailability of topical HA, although these technologies mostly remain at the experimental stage (reviewed in ${ }^{106}$ ). Robust penetration into deeper layers of the skin likely requires some form of assisted delivery however, with microneedling through the use of dermarollers, gliding or stamping microneedle devices, radiofrequency-based thermal needles, or fractionated lasers most commonly used. ${ }^{107}$ A related approach involves fabricating microneedles with HA itself to be applied to the skin in patches, resulting in clinical improvements in aging endpoints such as wrinkling and dermal density, and forms the basis of a delivery system for other anti-aging compounds. ${ }^{108,109}$ 


\section{Raw Material Approaches to Modulate GAG Levels in the Skin}

Indirect approaches to increase GAG content, particularly HA, are a common skincare raw material development strategy, however it is often difficult to determine if the modulation of GAG is a cause or consequence of the improved skin quality imparted by a treatment. Topical treatment with alpha hydroxy acids (AHA) for skin peeling results in increasing total GAG content ${ }^{110}$ and HA levels ${ }^{111}$ within the regenerated skin, correlating improved skin quality with elevated GAG levels. While improved skin appearance following skin peel treatment is consistent with the expected biological outcomes following restoration of GAG levels and function in aged skin, there is no evidence they act in a specific manner to induce GAG synthesis as opposed to synthesis occurring during AHAinduced general skin repair processes.

Direct modulation of GAG levels within the skin via topical small molecules or extracts has two possible strategies: downregulate factors that promote GAG degradation, or to increase GAG levels through the promotion of GAG synthesis. While the exogenous addition of hyaluronidase is common within medical aesthetics to break down injected HA fillers where the results did not match expectation or in cases of allergic reactions to the filler, it also represents a target for increasing endogenous HA levels within the skin. Sodium copper chlorophyllin is a relatively common cosmeceutical ingredient as a colorant, antioxidant and anti-bacterial, however it has also been demonstrated to inhibit hyaluronidase in vitro. ${ }^{112}$ Clinical studies have demonstrated that topical treatment using sodium copper chlorophyllin complexes improves the cosmetic quality of photoaged skin and increases cutaneous GAG levels, which is speculated by the authors to be the result of hyaluronidase inhibition. ${ }^{112-114}$ Despite these encouraging results, strategies aimed at modulating GAG levels in skin more commonly target directly increasing GAG production. ${ }^{4}$

Expression of HAS gene mRNA or HA production is one of the most common experimental endpoints for cosmetic raw material (RM) evaluation, and thus compounds or extracts that exhibit effects on this pathway are not few. Transcriptional regulation of the HAS1-3 genes is mediated by a broad family of growth factors and cytokines, with EGF, FGF, TGF- $\beta$ and IFN- $1 \beta$ particularly prominent. ${ }^{115,116}$ In general terms, factors that increase keratinocyte proliferation and migration such as EGF and
KGF stimulate HAS2 and HAS3, while those that suppress keratinocyte growth and increase differentiation such as TGF- $\beta$ decrease HA synthesis. ${ }^{117}$ Hyaluronic acid synthesis can also be regulated by control of precursors UDPGlucuronic acid and UDP-GlcNAc, post-transcriptional modulation of HAS activity or HAS phosphorylation, ${ }^{116}$ resulting in a diverse set of mechanisms through which cosmetic materials can modulate HAS expression and HA production within skin. Table 3 summarizes cosmetic preparations with clinical evidence of efficacy that are also known to increase HA levels or act on the HA pathway. The effect of retinol family compounds on cutaneous GAG is particularly complex. Tretinoin (all-trans retinoic acid) and isotretinoin are typically used for medical aesthetics/ dermatological purposes, while retinol and retinol esters are commonly found in cosmetic formulations. The HAS promoter region contains response elements for the retinoic acid receptor and thus is directly regulated via tretinoin, ${ }^{118}$ however signaling via EGF-R and HB-EGF is also an important aspect of retinoid-induced HA production and HAS induction within keratinocytes. ${ }^{117}$

Tretinoin also increases the synthesis of sulfated GAGs in cultured human fibroblasts, ${ }^{119}$ as well as within animal models. ${ }^{120}$ Margelin and colleagues also found that topical tretinoin treatment resulted in increased GAG synthesis in normal mice, particularly of DS. Curiously, tretinoin prevented the decline of GAG levels within the skin of UVB-exposed animals, although given the altered distribution of GAG deposition within UV exposed $\operatorname{skin}^{69}$ one may speculate that UV-induced aberrant GAG deposition on the elastic material of the papillary dermis was declining as the skin recovered, while beneficial GAG on collagen and elastin fibres was increased by tretinoin treatment. The increase of GAG levels within animal models are consistent with the clinical work of Kafi and colleagues, who found that treatment with a $0.4 \%$ retinol formulation increased total cutaneous GAG levels as determined by immunostaining. ${ }^{121}$ Chajra and co-workers utilized a similar strategy for boosting sulfated GAG levels with a formulation containing GAG precursors and synthesis intermediaries, finding it increased sulfated GAG levels within cultured human skin fibroblasts and ex vivo human skin, while improving dermal structure of ex vivo skin samples and increasing skin smoothness in a cohort of female volunteers. ${ }^{122}$ Jasmonic acid derivatives (JAD) have also been demonstrated to increase proteoglycan expression and modify GAG fine structure in skin, as well as potentiate KGF signaling. Consistent with these in vitro data, JAD treatment 
Table 3 Cosmetic RMs with Clinical Data That Act on HA

\begin{tabular}{|c|c|c|c|}
\hline $\mathbf{R M}$ & HA Activity & Clinical Benefit & Ref \\
\hline$J A D$ & $\begin{array}{l}\uparrow \text { HAS2 \& HAS3 mRNA, No change in CD44 } \\
\uparrow \text { HA expression (3D model) }\end{array}$ & $\begin{array}{l}\text { Improvements in the appearance of wrinkles, texture, and } \\
\text { pores }\end{array}$ & {$[148,149]$} \\
\hline Tetrapeptide GEKG & $\begin{array}{l}\uparrow \text { HASI mRNA (primary human foreskin } \\
\text { fibroblasts), } \uparrow \text { HA expression (ex vivo IHC) }\end{array}$ & $\begin{array}{l}\uparrow 41 \% \text { elasticity on inner forearm, } \downarrow 42 \% \text { skin wrinkle } \\
\text { depth, } \downarrow 9.5 \% \text { periorbital wrinkle }\end{array}$ & [150] \\
\hline Peptide pal-KTTKS & $\begin{array}{l}\uparrow \text { HASI mRNA (primary human fibroblasts), } \\
\uparrow \text { HA expression (ex vivo IHC) }\end{array}$ & $\begin{array}{l}\uparrow 36 \% \text { elasticity on inner forearm } \\
\downarrow 18 \% \text { skin wrinkle depth }\end{array}$ & {$[150]$} \\
\hline $\begin{array}{l}\text { Isosorbide } \\
\text { dicaprylate }\end{array}$ & $\uparrow$ CD44 mRNA (3D model) & $\begin{array}{l}\text { Improvement in skin hydration }(34.5 \% \text { for moderate dry } \\
\text { skin and } 133 \% \text { for severe dry skin), } 15 \% \text { reduction in } \\
\text { TEWL }\end{array}$ & {$[151]$} \\
\hline $\mathrm{N}$-acetylglucosamine & $\begin{array}{l}\text { No effects on HAS- I/2/3 mRNA (HDF), } \uparrow \\
\text { HA synthesis (HDF) }\end{array}$ & Reduced the appearance of facial hyperpigmentation & {$[152,153]$} \\
\hline $\mathrm{N}$-acetylcysteine & $\uparrow$ HAS and hyaluronidase mRNA (HDF) & $\begin{array}{l}\text { Improvement in skin hydration } \\
\text { Reduction in TEWL }\end{array}$ & {$[154,155]$} \\
\hline L-ascorbic acid & $\begin{array}{l}\downarrow \text { HAS2, CD44, HYALI \& HYAL2 mRNA. No } \\
\text { change in HASI and HAS3 mRNA (3D } \\
\text { model) }\end{array}$ & Improvements in skin wrinkling and skin roughness & {$[156-158]$} \\
\hline $\begin{array}{l}\text { Retinoic acid and } \\
\text { derivatives }\end{array}$ & $\begin{array}{l}\uparrow \text { Binding to HA promoter, } \uparrow \text { CD44 } \\
\text { expression, HA production (NEK) }\end{array}$ & $\begin{array}{l}\text { Improvements in skin wrinkling, barrier function and } \\
\text { hydration }\end{array}$ & {$[117,118,159]$} \\
\hline $\begin{array}{l}\text { Epigallocatechin- } \\
\text { 3-Gallate }\end{array}$ & $\uparrow \mathrm{HA}$ expression (IHC, ex vivo skin) & Reduced redness and flattened scars & {$[160]$} \\
\hline $\begin{array}{l}\text { Sanguisorba officinalis } \\
\text { root extract }\end{array}$ & $\uparrow \mathrm{HMW}-\mathrm{HA}$ synthesis (HDF) & Improved skin elasticity, reduced wrinkling & {$[161]$} \\
\hline $\begin{array}{l}\text { Isosorbide } \\
\text { dicaprylate }\end{array}$ & $\uparrow$ CD44 mRNA (3D skin) & $\begin{array}{l}\text { Improvement in skin hydration ( } 34.5 \% \text { for moderate dry } \\
\text { skin and } 133 \% \text { for severe dry skin) }\end{array}$ & {$[151]$} \\
\hline HA5 & $\uparrow$ HAS mRNA & $\begin{array}{l}\text { Improvements in fine lines/wrinkles, tactile roughness, } \\
\text { and skin hydration }\end{array}$ & [162] \\
\hline TRMT & $\begin{array}{l}\uparrow \text { HAS mRNA, } \downarrow \text { Hyaluronidase mRNA } \\
\text { (Human Epidermis) }\end{array}$ & $\begin{array}{l}\text { Improvements in fine lines/wrinkles, brightness, texture } \\
\text { and hydration }\end{array}$ & [163] \\
\hline
\end{tabular}

Notes: $\uparrow$ denotes increase in expression; $\downarrow$ a decrease; 3D skin denotes data obtained in 3D reconstructed skin models; IHC denotes immunohistochemistry; HDF denotes Human Dermal Fibroblasts; NEK denotes Normal Human Primary Keratinocytes.

promotes re-epithelialization clinically within a suction-cup blister model of wound healing. ${ }^{164}$

A key approach for modulation of GAGs involves the use of xylosides, members of the glycoside family that consist of a xylose attached to an aglycone that can act as competitors for GAGs to attach to their core protein. This results in synthesis of proteoglycans that have fewer GAG chains attached, while the xyloside can act as the core tetrasaccharide linker for the assembly of soluble GAG, resulting in GAG being synthesized onto the xyloside itself and subsequently secreted from the cell. ${ }^{123}$ Xylosides tend to make 5-20 times more GAG chains than endogenous core proteins, resulting in greatly potentiated free GAG levels. ${ }^{124}$ The most successful for skincare application has been C-xyloside, which is synthesized according to green chemistry principles ${ }^{125}$ and commercialized under the name Pro-Xylane ${ }^{\mathrm{TM}}$.

Using a 2D fibroblast culture system, Pineau and coworkers compared the GAG-inducing properties of $\mathrm{C}$-xyloside to those of $\beta$-xylosides, known potent GAG inducers (particularly of CS, DS and in some cases HS), but have poor stability that compromises their biological utility. ${ }^{126-128} \mathrm{C}$-xyloside induced an overall increase in fibroblast GAG synthesis profile and magnitude similar to that of $\beta$-xyloside, with particularly increased levels of single chain GAGs likely to be DS. ${ }^{129} \mathrm{C}$-xyloside also 


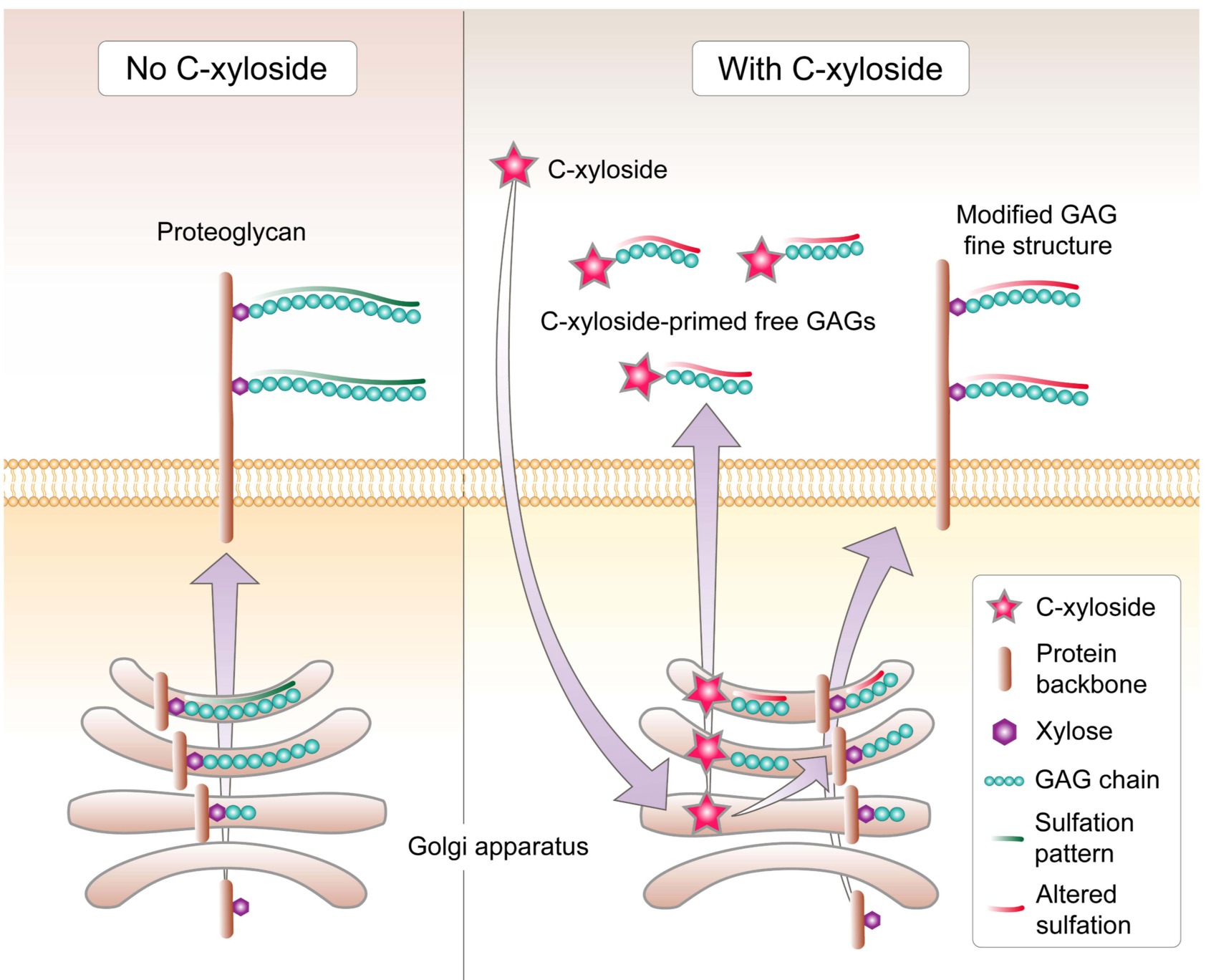

Figure 3 Mechanism of GAG alterations by C-xyloside. Under homeostasis, GAG chains are attached to the xyloside residue of a protein backbone followed by sulfation, and the newly-formed chain is transported to the cell membrane as a membrane-associated complex or released into the extracellular space. C-xyloside penetrates the cell membrane and acts as the primer for the core tetrasaccharide to assemble GAG chains on, which are then released as soluble GAG. These soluble chains are considerably shorter than in the absence of C-xyloside, and are predominately DS in keratinocytes, CS/DS in fibroblasts, and exhibit altered sulfation patterns. The levels of proteoglycan-associated GAG chains are not significantly reduced, but they too are shorter and exhibit altered sulfation patterns, including for HS.

promotes production of CS/DS in keratinocytes with the majority of secreted GAG being DS, with these chains being considerably shorter than native GAG and exhibiting altered sulfation patterns. ${ }^{130}$ Similar trends were observed in a reconstructed dermis model, with C-xyloside greatly potentiating the secretion of free CS/ DS which featured reduced chain sizes, increased O-sulfation, and altered iduronic acid content and distribution. ${ }^{123}$ While there was no reduction in proteoglycan-associated GAG chain levels unlike that imparted by other xylosides, ${ }^{16}$ treatment with $\mathrm{C}$-xyloside also resulted in shorted GAG chain length and altered sulfation patterns, particularly in the CS/DS 4-O/6-O sulfation ratio (Figure 3). ${ }^{123}$ Similarly, while HS levels were unchanged by $\mathrm{C}$-xyloside treatment, there was a strong reduction in sulfation content, particularly 6-O sulfation (Figure 3). C-xyloside promoted FGF-10-dependent keratinocyte migration and cell proliferation within a $2 \mathrm{D}$ keratinocyte scratch test model in a similar manner to groups treated with DS directly. ${ }^{130}$ These results are likely due to C-xyloside increasing DS levels within the culture that are essential for FGF-10 function on keratinocytes, ${ }^{131}$ and provide proof-of-concept for the ability of $\mathrm{C}$-xyloside to support in vitro growth factor activity via GAG production.

C-xyloside treatment within organotypic 3D reconstructed skin resulted in improved preserved skin architecture, with potentiated deposition of key DEJ proteins laminin 5 (which 


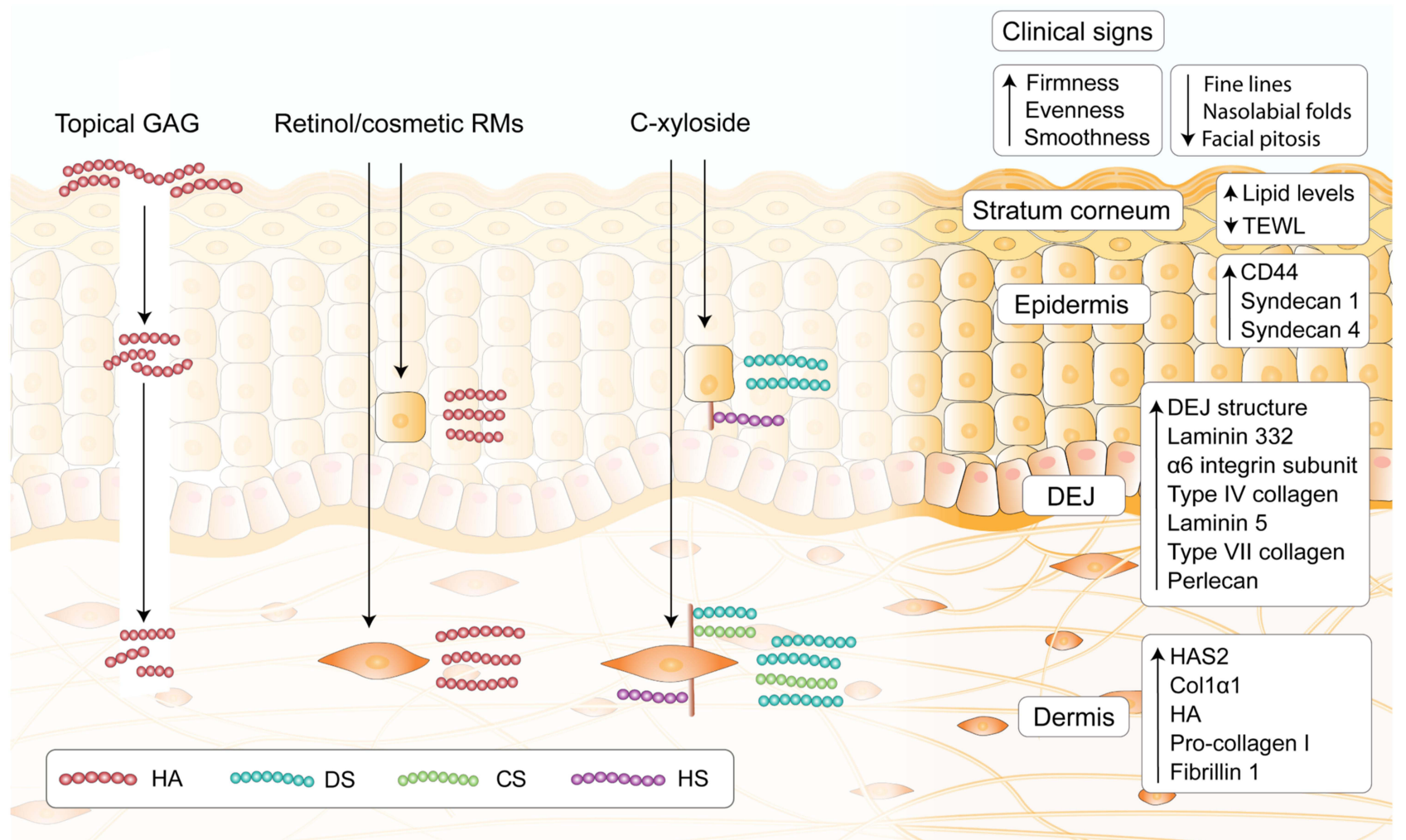

Figure 4 Main strategies of exploiting GAGs for skincare. Topical administration of GAGs such as HA results in topical occlusive effects, and may be able to penetrate into the upper layers of the stratum corneum. Evidence for deeper penetration remains inconclusive, however the use of assisted delivery approaches to create channels in skin through which HA can penetrate such as microneedles and lasers are commonly found in dermatology offices. Retinol and many other cosmetic RMs are able to act on keratinocytes or fibroblasts to potentiate endogenous HA production. C-xyloside increases endogenous GAG release, particularly short chains of CS/DS and alter the fine structure of proteoglycan-associated GAGs. GAG modulation with C-xyloside and associated approaches induce perceivable improvement in clinical signs, as well as inducing biological activity in the stratum corneum, epidermis, DEJ and the dermis as determined by clinical/in vitro data.

anchors microfilaments that connect the hemidesmosomes and the lamina densa), Type IV collagen (a major component of the lamina densa), and Type VII collagen (corresponding to anchoring fibrils). ${ }^{132}$ These proteins collectively act to strengthen the attachment of keratinocytes to the basement membrane, promoting dermal-epidermal adherence required for skin cohesion and resistance to mechanical stress. ${ }^{133,134}$ Similar data have been noted within the organotypic model of corticosteroid atrophic human skin, where repeated treatment with C-xyloside restored the levels of CD44, perlecan and syndecan 1 and 4 expression back to those observed within control skin. ${ }^{135}$

These in vitro study results of the beneficial effects of GAG modulation have been extended to clinical findings. Three months of daily $\mathrm{C}$-xyloside treatment results in improvements in clinical aging endpoints, with the development of a more homogeneous and regular lamina densa of the DEJ as determined by transmission electron microscopy evaluation, and a concomitant increase in laminin-332 and its $\alpha 6$ integrin subunit which are implicated in DEJ resistance to mechanical stress, ${ }^{133}$ DEJ component localization ${ }^{136}$ and basement membrane formation. ${ }^{137}$ These data are consistent with clinical results using a topical formulation containing $\mathrm{C}$-xyloside and an AGE-inhibiting blueberry extract in a cohort of 20 type IIdiabetic female patients, a group that demonstrates increased levels of AGE and therefore represents a clinical model of accelerated aging. Twice daily treatment with the formula over 12 weeks resulted in significant improvements in clinical endpoints of skin quality such as fine lines, firmness, radiance, skin tone evenness, smoothness and overall skin appearance. ${ }^{138}$ Similarly, a clinical study utilizing a multi-modal facial serum containing $\mathrm{C}$-xyloside, HA and a number of natural extracts and examining wrinkle dimensions (length, depth and width), skin density and transepidermal water loss (TEWL) on a 59-person cohort of women with mild-tomoderate facial damage demonstrated significant improvements across all clinical endpoints measured, and by week 12 there were also significant improvements in SC hydration and TEWL, as well as increased skin HA levels, HAS2 and Coll $\alpha 1$ 
within biopsied skin sections isolated from the volunteers. ${ }^{139}$ Finally, a multi-center, blinded and randomized study of 240 healthy, post-menopausal women using a skincare complex with a backbone of 3\% C-xyloside exhibited statistically significant improvements in facial ptosis, neck folds, nasolabial folds, skin radiance and complexion evenness as determined by blinded clinical assessment, with an accompanying improvement in skin lipid profile. ${ }^{140}$ These data collectively demonstrate the efficacy of approaches aimed at modulating endogenous sulfated GAGs within the skin, and may form the basis of future developments focusing on CS/DS and/or HS. The key approaches for increasing GAG levels within the skin, and published resultant changes in skin physiology are summarized in Figure 4.

\section{Conclusion}

Glycosaminoglycans form an integral part of the skin, and the alteration of GAG and proteoglycan form and function during both intrinsic and extrinsic aging demonstrates their utility as a target for improving ageassociated declines in skin quality. While the benefit of direct topical GAG administration such as HAcontaining formulas is well established, approaches utilizing molecules or extracts to promote GAG release within the skin such as C-xyloside are also clearly beneficial, and represent a promising target for future development of topical skincare solutions.

\section{Acknowledgments}

We would like to thank Dr Diah Bramono for the helpful discussions and critical reading of the manuscript, and Dr Isabelle Castiel for her guidance.

\section{Disclosure}

Ms Wang was an employee of L'Oréal Research \& Innovation at the time the study was conducted. Mr Neo and Dr Betts are employees of L'Oréal Research \& Innovation. The authors report no other conflicts of interest in this work.

\section{References}

1. Esko JD, Kimata K, Lindahl U. Proteoglycans and sulfated glycosaminoglycans. In: Essentials of Glycobiology. Cold Spring Harbor (NY); 2009.

2. Jackson RL, Busch SJ, Cardin AD. Glycosaminoglycans: molecular properties, protein interactions, and role in physiological processes. Physiol Rev. 1991;71(2):481-539. doi:10.1152/physrev.1991.71.2.481
3. Couchman JR, Pataki CA. An introduction to proteoglycans and their localization. J Histochem Cytochem. 2012;60(12):885-897. doi:10.1369/0022155412464638

4. Nadanaka S, Purunomo E, Takeda N, et al. Heparan sulfate containing unsubstituted glucosamine residues: biosynthesis and heparanase-inhibitory activity. $J$ Biol Chem. 2014;289 (22):15231-15243. doi:10.1074/jbc.M113.545343

5. Yu P, Pearson CS, Geller HM. Flexible roles for proteoglycan sulfation and receptor signaling. Trends Neurosci. 2018;41 (1):47-61. doi:10.1016/j.tins.2017.10.005

6. Merida-de-barros DA, Chaves SP, Belmiro CLR, et al. Leishmaniasis and glycosaminoglycans: a future therapeutic strategy? Parasit Vectors. 2018;11(1):536. doi:10.1186/s13071-018-2953-y

7. Malmstrom A, Bartolini B, Thelin MA, et al. Iduronic acid in chondroitin/dermatan sulfate: biosynthesis and biological function. J Histochem Cytochem. 2012;60(12):916-925. doi:10.1369/ 0022155412459857

8. Silbert JE, Palmer ME, Humphries DE, et al. Formation of dermatan sulfate by cultured human skin fibroblasts. Effects of sulfate concentration on proportions of dermatan/chondroitin. $J$ Biol Chem. 1986;261(29):13397-13400. doi:10.1016/S00219258(18)67029-2

9. Trowbridge JM, Gallo RL. Dermatan sulfate: new functions from an old glycosaminoglycan. Glycobiology. 2002;12(9):117R125R. doi:10.1093/glycob/cwf066

10. Li JP. Glucuronyl C5-epimerase an enzyme converting glucuronic acid to iduronic acid in heparan sulfate/heparin biosynthesis. Prog Mol Biol Transl Sci. 2010;93:59-78.

11. Carlsson P, Kjellen L. Heparin biosynthesis. Handb Exp Pharmacol. 2012;207:23-41.

12. Lindahl U, Couchman J, Kimata K, Esko JD. Proteoglycans and sulfated glycosaminoglycans. In: Essentials of Glycobiology. Cold Spring Harbor (NY); 2015:207-221.

13. Collins LE, Troeberg L. Heparan sulfate as a regulator of inflammation and immunity. J Leukoc Biol. 2019;105(1):81-92. doi:10.1002/JLB.3RU0618-246R

14. Esko JD, Selleck SB. Order out of chaos: assembly of ligand binding sites in heparan sulfate. Annu Rev Biochem. 2002;71 (1):435-471. doi:10.1146/annurev.biochem.71.110601.135458

15. Kreuger J, Kjellen L. Heparan sulfate biosynthesis: regulation and variability. $J$ Histochem Cytochem. 2012;60(12):898-907. doi:10.1369/0022155412464972

16. Chua JS, Kuberan B. Synthetic xylosides: probing the glycosaminoglycan biosynthetic machinery for biomedical applications. Acc Chem Res. 2017;50(11):2693-2705. doi:10.1021/acs. accounts. $7 \mathrm{~b} 00289$

17. Stern R, Maibach HI. Hyaluronan in skin: aspects of aging and its pharmacologic modulation. Clin Dermatol. 2008;26(2):106-122. doi:10.1016/j.clindermatol.2007.09.013

18. Anderegg U, Simon JC, Averbeck M. More than just a filler - the role of hyaluronan for skin homeostasis. Exp Dermatol. 2014;23 (5):295-303. doi:10.1111/exd.12370

19. Lee DH, Oh JH, Chung JH. Glycosaminoglycan and proteoglycan in skin aging. J Dermatol Sci. 2016;83(3):174-181. doi:10.1016/j. jdermsci.2016.05.016

20. Suzu S, Kimura F, Yamada M, et al. Direct interaction of proteoglycan macrophage colony-stimulating factor and basic fibroblast growth factor. Blood. 1994;83(11):3113-3119. doi:10.1182/blood. V83.11.3113.3113

21. Corsi A, Xu T, Chen X-D, et al. Phenotypic effects of biglycan deficiency are linked to collagen fibril abnormalities, are synergized by decorin deficiency, and mimic Ehlers-Danloslike changes in bone and other connective tissues. $J$ Bone Miner Res. 2002;17(7):1180-1189. doi:10.1359/ jbmr.2002.17.7.1180 
22. Reinboth B, Hanssen E, Cleary EG, et al. Molecular interactions of biglycan and decorin with elastic fiber components: biglycan forms a ternary complex with tropoelastin and microfibril-associated glycoprotein 1. J Biol Chem. 2002;277 (6):3950-3957. doi:10.1074/jbc.M109540200

23. Carrino DA, Calabro A, Darr AB, et al. Age-related differences in human skin proteoglycans. Glycobiology. 2011;21(2):257-268. doi:10.1093/glycob/cwq162

24. Bishop JR, Schuksz M, Esko JD. Heparan sulphate proteoglycans fine-tune mammalian physiology. Nature. 2007;446 (7139):1030-1037. doi:10.1038/nature05817

25. Kvist AJ, Johnson AE, Mörgelin M, et al. Chondroitin sulfate perlecan enhances collagen fibril formation. Implications for perlecan chondrodysplasias. J Biol Chem. 2006;281(44):33127-33139. doi:10.1074/jbc.M607892200

26. Qwarnstrom EE, Järveläinen HT, Kinsella MG, et al. Interleukin$1 \beta$ regulation of fibroblast proteoglycan synthesis involves a decrease in versican steady-state mRNA levels. Biochem J. 1993;294(2):613-620. doi:10.1042/bj2940613

27. Tufvesson E, Westergren-Thorsson G. Alteration of proteoglycan synthesis in human lung fibroblasts induced by interleukin-1beta and tumor necrosis factor-alpha. J Cell Biochem. 2000;77(2):298-309. doi:10.1002/(SICI)1097-4644(20000501)77:2<298::AID-JCB12>3. $0 . \mathrm{CO} ; 2-\mathrm{D}$

28. Duncan MR, Berman B. Differential regulation of glycosaminoglycan, fibronectin, and collagenase production in cultured human dermal fibroblasts by interferon-alpha, -beta, and -gamma. Arch Dermatol Res. 1989;281(1):11-18. doi:10.1007/BF00424266

29. Duncan MR, Berman B. Differential regulation of collagen, glycosaminoglycan, fibronectin, and collagenase activity production in cultured human adult dermal fibroblasts by interleukin 1-alpha and beta and tumor necrosis factor-alpha and beta. J Invest Dermatol. 1989;92 (5):699-706. doi:10.1016/0022-202X(89)90185-1

30. Kinsella MG, Bressler SL, Wight TN. The regulated synthesis of versican, decorin, and biglycan: extracellular matrix proteoglycans that influence cellular phenotype. Crit Rev Eukaryot Gene Expr. 2004;14(3):203-234. doi:10.1615/CritRevEukaryotGeneExpr.v14. i3.40

31. Tan EM, Hoffren J, Rouda S, et al. Decorin, versican, and biglycan gene expression by keloid and normal dermal fibroblasts: differential regulation by basic fibroblast growth factor. Exp Cell Res. 1993;209(2):200-207. doi:10.1006/excr.1993.1302

32. Bansal R, Kumar M, Murray K, et al. Developmental and FGF2-mediated regulation of syndecans (1-4) and glypican in oligodendrocytes. Mol Cell Neurosci. 1996;7(4):276-288. doi:10.1006/ mcne.1996.0021

33. Jaakkola P, Jalkanen M. Transcriptional regulation of Syndecan-1 expression by growth factors. Prog Nucleic Acid Res Mol Biol. 1999;63:109-138.

34. Varma RS, Varma R. Glycosaminoglycans and Proteoglycans of Skin, in Glycosaminoglycans and Proteoglycans in Physiological and Pathological Processes of Body Systems. Karger Publishers; 1982:151-164.

35. Maccari F, Volpi N. Structural characterization of the skin glycosaminoglycans in patients with pseudoxanthoma elasticum. Int J Dermatol. 2008;47(10):1024-1027. doi:10.1111/j.13654632.2008.03762.x

36. Oh JH, Shin MK, Lee H, et al. Analysis of sulfated glycosaminoglycan composition change in intrinsically aged and photoaged human skin using an enzymatic degradation method. J Dermatol Sci. 2018;92(3):281-283. doi:10.1016/j. jdermsci.2018.10.003

37. Willen MD, Sorrell JM, Lekan CC, et al. Patterns of glycosaminoglycan/proteoglycan immunostaining in human skin during aging. J Invest Dermatol. 1991;96(6):968-974. doi:10.1111/ 1523-1747.ep12476335
38. Kiani $\mathrm{C}$, Chen $\mathrm{L}, \mathrm{Wu} \mathrm{YJ}$, et al. Structure and function of aggrecan. Cell Res. 2002;12(1):19-32. doi:10.1038/sj.cr.7290106

39. Fuchs K, Hippe A, Schmaus A, et al. Opposing effects of highand low-molecular weight hyaluronan on CXCL12-induced CXCR4 signaling depend on CD44. Cell Death Dis. 2013;4(10): e819. doi:10.1038/cddis.2013.364

40. Gariboldi S, Palazzo M, Zanobbio L, et al. Low molecular weight hyaluronic acid increases the self-defense of skin epithelium by induction of beta-defensin 2 via TLR2 and TLR4. J Immunol. 2008;181(3):2103-2110. doi:10.4049/jimmunol.181.3.2103

41. Foschi D, Castoldi L, Radaelli E, et al. Hyaluronic acid prevents oxygen free-radical damage to granulation tissue: a study in rats. Int J Tissue React. 1990;12(6):333-339.

42. Trabucchi E, Pallotta S, Morini M, et al. Low molecular weight hyaluronic acid prevents oxygen free radical damage to granulation tissue during wound healing. Int J Tissue React. 2002;24 (2):65-71

43. Weiss JM, Renkl AC, Sleeman J, et al. CD44 variant isoforms are essential for the function of epidermal Langerhans cells and dendritic cells. Cell Adhes Commun. 1998;6(2-3):157-160. doi:10.3109/15419069809004472

44. Bourguignon LY, Ramez M, Gilad E, et al. Hyaluronan-CD44 interaction stimulates keratinocyte differentiation, lamellar body formation/secretion, and permeability barrier homeostasis. $J$ Invest Dermatol. 2006;126(6):1356-1365. doi:10.1038/sj.jid.5700260

45. Kavasi RM, Berdiaki A, Spyridaki I, et al. HA metabolism in skin homeostasis and inflammatory disease. Food Chem Toxicol. 2017;101:128-138. doi:10.1016/j.fct.2017.01.012

46. Wolny PM, Banerji S, Gounou C, et al. Analysis of CD44-hyaluronan interactions in an artificial membrane system: insights into the distinct binding properties of high and low molecular weight hyaluronan. J Biol Chem. 2010;285 (39):30170-30180. doi:10.1074/jbc.M110.137562

47. Maquart FX, Brézillon S, Wegrowski Y. Proteoglycans in Skin Aging. Heidelberg: Springer Berlin Heidelberg; 2010:109-120.

48. Pang X, Dong N, Zheng Z. Small leucine-rich proteoglycans in skin wound healing. Front Pharmacol. 2019;10:1649.

49. Nomura Y. Structural change in decorin with skin aging. Connect Tissue Res. 2006;47(5):249-255. doi:10.1080/03008200600846606

50. Kosho T. CHST14/D4ST1 deficiency: new form of Ehlers-Danlos syndrome. Pediatr Int. 2016;58(2):88-99. doi:10.1111/ped.12878

51. Miyake N, Kosho T, Mizumoto S, et al. Loss-of-function mutations of CHST14 in a new type of Ehlers-Danlos syndrome. Hum Mutat. 2010;31(8):966-974. doi:10.1002/humu.21300

52. Hirose T, Mizumoto S, Hashimoto A, et al. Systematic investigation of the skin in Chst14-/- mice: a model for skin fragility in musculocontractural Ehlers-Danlos syndrome caused by CHST14 variants (mcEDS-CHST14). Glycobiology. 2021;31:137-150.

53. Li Y, Liu Y, Xia W, et al. Age-dependent alterations of decorin glycosaminoglycans in human skin. Sci Rep. 2013;3(1):2422. doi:10.1038/srep02422

54. Schonherr E, Witsch-Prehm P, Harrach B, et al. Interaction of biglycan with type I collagen. J Biol Chem. 1995;270 (6):2776-2783. doi:10.1074/jbc.270.6.2776

55. Liu XJ, Kong FZ, Wang YH, et al. Lumican accelerates wound healing by enhancing alpha2beta1 integrin-mediated fibroblast contractility. PLoS One. 2013;8(6):e67124. doi:10.1371/journal. pone. 0067124

56. Zimmermann DR, Dours-Zimmermann MT, Schubert M, et al. Versican is expressed in the proliferating zone in the epidermis and in association with the elastic network of the dermis. $J$ Cell Biol. 1994;124(5):817-825. doi:10.1083/jcb.124.5.817

57. Hattori N, Carrino DA, Lauer ME, et al. Pericellular versican regulates the fibroblast-myofibroblast transition: a role for ADAMTS5 protease-mediated proteolysis. $J$ Biol Chem. 2011;286(39):34298-34310. doi:10.1074/jbc.M111.254938 
58. Brown JC, Sasaki T, Gohring W, et al. The C-terminal domain $\mathrm{V}$ of perlecan promotes beta1 integrin-mediated cell adhesion, binds heparin, nidogen and fibulin-2 and can be modified by glycosaminoglycans. Eur $J$ Biochem. 1997;250(1):39-46. doi:10.1111/j.1432-1033.1997.t01-1-00039.x

59. Sher I, Zisman-Rozen S, Eliahu L, et al. Targeting perlecan in human keratinocytes reveals novel roles for perlecan in epidermal formation. J Biol Chem. 2006;281(8):5178-5187. doi:10.1074/jbc.M509500200

60. Chung H, Multhaupt HAB, Oh E-S, et al. Minireview: syndecans and their crucial roles during tissue regeneration. FEBS Lett. 2016;590(15):2408-2417. doi:10.1002/1873-3468.12280

61. Echtermeyer F, Streit M, Wilcox-Adelman S, et al. Delayed wound repair and impaired angiogenesis in mice lacking syndecan-4. J Clin Invest. 2001;107(2):R9-R14. doi:10.1172/JCI10559

62. Stepp MA, Gibson HE, Gala PH, et al. Defects in keratinocyte activation during wound healing in the syndecan-1-deficient mouse. J Cell Sci. 2002;115(23):4517-4531. doi:10.1242/jcs.00128

63. Gopal S. Syndecans in inflammation at a glance. Front Immunol. 2020;11:227. doi:10.3389/fimmu.2020.00227

64. Farage MA, Miller KW, Elsner P, et al. Intrinsic and extrinsic factors in skin ageing: a review. Int J Cosmet Sci. 2008;30 (2):87-95. doi:10.1111/j.1468-2494.2007.00415.x

65. Shin JW, Kwon SH, Choi JY, et al. Molecular mechanisms of dermal aging and antiaging approaches. Int J Mol Sci. 2019;20 (9):2126. doi:10.3390/ijms20092126

66. Oh JH, Kim YK, Jung JY, et al. Changes in glycosaminoglycans and related proteoglycans in intrinsically aged human skin in vivo. Exp Dermatol. 2011;20(5):454-456. doi:10.1111/j.16000625.2011.01258.x

67. Coolen NA, Schouten KCWM, Middelkoop E, et al. Comparison between human fetal and adult skin. Arch Dermatol Res. 2010;302(1):47-55. doi:10.1007/s00403-009-0989-8

68. Werth BB, Bashir M, Chang L, et al. Ultraviolet irradiation induces the accumulation of chondroitin sulfate, but not other glycosaminoglycans, in human skin. PLoS One. 2011;6(8): e14830. doi:10.1371/journal.pone.0014830

69. Bernstein EF, Fisher LW, Li K, et al. Differential expression of the versican and decorin genes in photoaged and sun-protected skin. Comparison by immunohistochemical and northern analyses. Lab Invest. 1995;72(6):662-669.

70. Tzellos TG, Sinopidis X, Kyrgidis A, et al. Differential hyaluronan homeostasis and expression of proteoglycans in juvenile and adult human skin. $J$ Dermatol Sci. 2011;61(1):69-72. doi:10.1016/j.jdermsci.2010.10.010

71. Tzellos TG, Klagas I, Vahtsevanos K, et al. Extrinsic ageing in the human skin is associated with alterations in the expression of hyaluronic acid and its metabolizing enzymes. Exp Dermatol. 2009;18(12):1028-1035. doi:10.1111/j.1600-0625.2009.00889.x

72. Rock K, Grandoch M, Majora M, et al. Collagen fragments inhibit hyaluronan synthesis in skin fibroblasts in response to ultraviolet B (UVB): new insights into mechanisms of matrix remodeling. J Biol Chem. 2011;286(20):18268-18276. doi:10.1074/jbc.M110.201665

73. Dos Santos M, Michopoulou A, André-Frei V, et al. Perlecan expression influences the keratin 15-positive cell population fate in the epidermis of aging skin. Aging. 2016;8(4):751-768. doi:10.18632/aging.100928

74. Cross M, Dexter TM. Growth factors in development, transformation, and tumorigenesis. Cell. 1991;64(2):271-280. doi:10.1016/0092-8674(91)90638-F

75. Demidova-Rice TN, Hamblin MR, Herman IM. Acute and impaired wound healing: pathophysiology and current methods for drug delivery, part 2: role of growth factors in normal and pathological wound healing: therapeutic potential and methods of delivery. Adv Skin Wound Care. 2012;25(8):349-370. doi:10.1097/01.ASW.0000418541.31366.a3
76. Pamela RD. Topical growth factors for the treatment of facial photoaging: a clinical experience of eight cases. J Clin Aesthet Dermatol. 2018;11(12):28-29.

77. de Araujo R, Lôbo M, Trindade K, et al. Fibroblast growth factors: a controlling mechanism of skin aging. Skin Pharmacol Physiol. 2019;32(5):275-282. doi:10.1159/000501145

78. Dou C, Lay F, Ansari AM, et al. Strengthening the skin with topical delivery of keratinocyte growth factor-1 using a novel DNA plasmid. Mol Ther. 2014;22(4):752-761. doi:10.1038/ mt.2014.2

79. Ha JM, Lim CA, Han K, et al. The effect of micro-spicule containing epidermal growth factor on periocular wrinkles. Ann Dermatol. 2017;29(2):187-193. doi:10.5021/ad.2017.29.2.187

80. Lyons A, Stoll J, Moy R. A randomized, double-blind, placebo-controlled, split-face study of the efficacy of topical epidermal growth factor for the treatment of melasma. J Drugs Dermatol. 2018;17(9):970-973.

81. Zeranska J, Pasikowska M, Szczepanik B, et al. A study of the activity and effectiveness of recombinant fibroblast growth factor (Q40P/S47I/ H93G rFGF-1) in anti-aging treatment. Postepy Dermatol Alergol. 2016;1(1):28-36. doi:10.5114/pdia.2014.44024

82. Damon DH, Lobb RR, D'Amore PA, et al. Heparin potentiates the action of acidic fibroblast growth factor by prolonging its biological half-life. J Cell Physiol. 1989;138(2):221-226. doi:10.1002/jcp.1041380202

83. Rival D, Bonnet S, Sohm B, et al. A Hibiscus Abelmoschus seed extract as a protective active ingredient to favour FGF-2 activity in skin. Int $J$ Cosmet Sci. 2009;31(6):419-426. doi:10.1111/ j.1468-2494.2009.00538.x

84. Zakrzewska M, Krowarsch D, Wiedlocha A, et al. Highly stable mutants of human fibroblast growth factor-1 exhibit prolonged biological action. J Mol Biol. 2005;352(4):860-875. doi:10.1016/ j.jmb.2005.07.066

85. Buchtova M, Chaloupkova R, Zakrzewska M, et al. Instability restricts signaling of multiple fibroblast growth factors. Cell Mol Life Sci. 2015;72(12):2445-2459. doi:10.1007/s00018-0151856-8

86. Clayton A, Thomas J, Thomas GJ, et al. Cell surface heparan sulfate proteoglycans control the response of renal interstitial fibroblasts to fibroblast growth factor-2. Kidney Int. 2001;59 (6):2084-2094. doi:10.1046/j.1523-1755.2001.00723.x

87. Peplow PV. Glycosaminoglycan: a candidate to stimulate the repair of chronic wounds. Thromb Haemost. 2005;94(1):4-16. doi:10.1160/TH04-12-0812

88. Shute J. Glycosaminoglycan and chemokine/growth factor interactions. Handb Exp Pharmacol. 2012;207:307-324.

89. Alexopoulou AN, Multhaupt HA, Couchman JR. Syndecans in wound healing, inflammation and vascular biology. Int J Biochem Cell Biol. 2007;39(3):505-528. doi:10.1016/j.biocel.2006.10.014

90. Taipale J, Keski-Oja J. Growth factors in the extracellular matrix. FASEB J. 1997;11(1):51-59. doi:10.1096/fasebj.11.1.9034166

91. Locci P, Marinucci L, Lilli C, et al. Transforming growth factor beta 1-hyaluronic acid interaction. Cell Tissue Res. 1995;281 (2):317-324. doi:10.1007/BF00583400

92. Pye DA, Gallagher JT. Monomer complexes of basic fibroblast growth factor and heparan sulfate oligosaccharides are the minimal functional unit for cell activation. J Biol Chem. 1999;274 (19):13456-13461. doi:10.1074/jbc.274.19.13456

93. Schlessinger J, Plotnikov AN, Ibrahimi OA, et al. Crystal structure of a ternary FGF-FGFR-heparin complex reveals a dual role for heparin in FGFR binding and dimerization. Mol Cell. 2000;6 (3):743-750. doi:10.1016/S1097-2765(00)00073-3

94. Venero Galanternik M, Kramer KL, Piotrowski T. Heparan sulfate proteoglycans regulate Fgf signaling and cell polarity during collective cell migration. Cell Rep. 2015;10(3):414-428. doi:10.1016/j.celrep.2014.12.043 
95. Bukhari SNA, Roswandi NL, Waqas M, et al. Hyaluronic acid, a promising skin rejuvenating biomedicine: a review of recent updates and pre-clinical and clinical investigations on cosmetic and nutricosmetic effects. Int J Biol Macromol. 2018;120(Pt B):1682-1695. doi:10.1016/j.ijbiomac.2018.09.188

96. Baumann L. How to use oral and topical cosmeceuticals to prevent and treat skin aging. Facial Plast Surg Clin North Am. 2018;26(4):407-413. doi:10.1016/j.fsc.2018.06.002

97. Hong CH, Schachter J, Sutton AB, et al. $89 \%$ Vichy mineralizing water with hyaluronic acid is a well-tolerated adjunct treatment that helps restore skin barrier function in dry skin-related inflammatory dermatoses and post-procedure skin care: a Canadian study. J Cosmet Dermatol. 2021;20(7):2148-2155. doi:10.1111/ jocd. 14116

98. Salsberg J, Andriessen A, Abdulla S, et al. A review of protection against exposome factors impacting facial skin barrier function with $89 \%$ mineralizing thermal water. $J$ Cosmet Dermatol. 2019;18(3):815-820. doi:10.1111/jocd.12927

99. Brown TJ, Alcorn D, Fraser JR. Absorption of hyaluronan applied to the surface of intact skin. J Invest Dermatol. 1999;113(5):740-746. doi:10.1046/j.1523-1747.1999.00745.x

100. Zhang $\mathrm{C}$, Zhang $\mathrm{K}$, Zhang J, et al. Skin delivery of hyaluronic acid by the combined use of sponge spicules and flexible liposomes. Biomater Sci. 2019;7(4):1299-1310. doi:10.1039/ C8BM01555D

101. Pavicic T, Gauglitz GG, Lersch P, et al. Efficacy of cream-based novel formulations of hyaluronic acid of different molecular weights in anti-wrinkle treatment. J Drugs Dermatol. 2011;10 (9):990-1000.

102. Gallo RL, Bucay VW, Shamban AT, et al. The potential role of topically applied heparan sulfate in the treatment of photodamage. J Drugs Dermatol. 2015;14(7):669-674.

103. Bucay V, Gold MH, Andriessen A. Low molecular weight heparan sulfate containing facial skin care for reducing inflammation and restoring aged-skin homeostasis. J Cosmet Dermatol. 2020;19(8):1851-1856. doi:10.1111/jocd.13528

104. Colvan L, Fleck T, Vega VL. Global periorbital skin rejuvenation by a topical eye cream containing low molecular weight heparan sulfate (LMW-HS) and a blend of naturally derived extracts. J Cosmet Dermatol. 2019;18(2):530-538. doi:10.1111/ jocd. 12857

105. Ito K, Yamada R, Matsumoto $\mathrm{N}$, et al. Evaluation of fibroblast growth factor activity exerted by placental extract used as a cosmetic ingredient. J Cosmet Dermatol. 2018;17(5):821-829. doi:10.1111/jocd.12434

106. Zhu J, Tang X, Jia Y, et al. Applications and delivery mechanisms of hyaluronic acid used for topical/transdermal delivery - a review. Int J Pharm. 2020;578:119127. doi:10.1016/j.ijpharm.2020.119127

107. Duncan DI. Microneedling with biologicals: advantages and limitations. Facial Plast Surg Clin North Am. 2018;26 (4):447-454. doi:10.1016/j.fsc.2018.06.006

108. Jang M, Baek S, Kang G, et al. Dissolving microneedle with high molecular weight hyaluronic acid to improve skin wrinkles, dermal density and elasticity. Int J Cosmet Sci. 2020;42(3):302-309. doi:10.1111/ics.12617

109. Kang G, Kim S, Yang H, et al. Combinatorial application of dissolving microneedle patch and cream for improvement of skin wrinkles, dermal density, elasticity, and hydration. $J$ Cosmet Dermatol. 2019;18(4):1083-1091. doi:10.1111/jocd.12807

110. Ditre CM, Griffin TD, Murphy GF, et al. Effects of $\alpha$-hydroxy acids on photoaged skin: a pilot clinical, histologic, and ultrastructural study. J Am Acad Dermatol. 1996;34(2):187-195. doi:10.1016/S0190-9622(96)80110-1

111. Bernstein EF, Lee J, Brown DB, et al. Glycolic acid treatment increases type I collagen $\mathrm{mRNA}$ and hyaluronic acid content of human skin. Dermatol Surg. 2001;27(5):429-433.
112. McCook JP, Dorogi P, Vasily D, et al. In vitro inhibition of hyaluronidase by sodium copper chlorophyllin complex and chlorophyllin analogs. Clin Cosmet Investig Dermatol. 2015;8:443-448. doi:10.2147/CCID.S86863

113. McCook JP, Stephens T, Jiang L, et al. Ability of sodium copper chlorophyllin complex to repair photoaged skin by stimulation of biomarkers in human extracellular matrix. Clin Cosmet Investig Dermatol. 2016;9:167-174. doi:10.2147/CCID.S111139

114. Sigler ML, Stephens TJ. Assessment of the safety and efficacy of topical copper chlorophyllin in women with photodamaged facial skin. J Drugs Dermatol. 2015;14(4):401-404.

115. Siiskonen H, Oikari S, Pasonen-SeppÃannen S, et al. Hyaluronan synthase 1: a mysterious enzyme with unexpected functions. Front Immunol. 2015;6:43. doi:10.3389/fimmu.2015.00043

116. Tammi RH, Passi AG, Rilla K, et al. Transcriptional and post-translational regulation of hyaluronan synthesis. FEBS J. 2011;278(9):1419-1428. doi:10.1111/j.1742-4658.2011.08070.x

117. Pasonen-Seppanen SM, Maytin EV, Törrönen KJ, et al. All-trans retinoic acid-induced hyaluronan production and hyperplasia are partly mediated by EGFR signaling in epidermal keratinocytes. $J$ Invest Dermatol. 2008;128(4):797-807. doi:10.1038/sj. jid.5701098

118. Makkonen KM, Pasonen-Seppänen S, Törrönen $\mathrm{K}$, et al. Regulation of the hyaluronan synthase 2 gene by convergence in cyclic AMP response element-binding protein and retinoid acid receptor signaling. J Biol Chem. 2009;284(27):18270-18281. doi:10.1074/jbc.M109.012492

119. Shapiro SS, Mott DJ. Modulation of glycosaminoglycan biosynthesis by retinoids. Ann N Y Acad Sci. 1981;359:306-321. doi:10.1111/j.1749-6632.1981.tb12756.x

120. Margelin D, Medaisko C, Lombard D, et al. Hyaluronic acid and dermatan sulfate are selectively stimulated by retinoic acid in irradiated and nonirradiated hairless mouse skin. $J$ Invest Dermatol. 1996;106(3):505-509. doi:10.1111/1523-1747. ep12343819

121. Kafi R, Kwak HSR, Schumacher WE, et al. Improvement of naturally aged skin with vitamin A (retinol). Arch Dermatol. 2007;143(5):606-612. doi:10.1001/archderm.143.5.606

122. Chajra H, Auriol D, Joly F, et al. Reactivating the extracellular matrix synthesis of sulfated glycosaminoglycans and proteoglycans to improve the human skin aspect and its mechanical properties. Clin Cosmet Investig Dermatol. 2016;9:461-472. doi: $10.2147 /$ CCID.S116548

123. Vassal-Stermann E, Duranton A, Black AF, et al. A New C-Xyloside induces modifications of GAG expression, structure and functional properties. PLoS One. 2012;7(10):e47933. doi:10.1371/journal.pone.0047933

124. Victor XV, Nguyen TKN, Ethirajan M, et al. Investigating the elusive mechanism of glycosaminoglycan biosynthesis. J Biol Chem. 2009;284(38):25842-25853. doi:10.1074/jbc.M109.043208

125. Anastas PT, Warner JC. Green Chemistry: Theory and Practice. Oxford England; New York: Oxford University Press; 1998:135.

126. Carrino DA, Caplan AI. The effects of $\beta$-d-xyloside on the synthesis of proteoglycans by skeletal muscle: lack of effect on decorin and differential polymerization of core protein-bound and xyloside-linked chondroitin sulfate. Matrix Biol. 1994;14(2):121-133. doi:10.1016/0945-053X(94)90002-7

127. Coster L, Hernnas J, Malmstrom A. Biosynthesis of dermatan sulphate proteoglycans. The effect of $\beta$-d-xyloside addition on the polymer-modification process in fibroblast cultures. Biochem $\mathrm{J}$. 1991;276(2):533-539. doi:10.1042/bj2760533

128. Johnston LS, Keller JM. The effect of beta-xylosides on heparan sulfate synthesis by SV40-transformed Swiss mouse 3T3 cells.. $J$ Biol Chem. 1979;254(8):2575-2578. doi:10.1016/S00219258(17)30107-2 
129. Pineau N, Carrino DA, Caplan AI, et al. Biological evaluation of a new C-xylopyranoside derivative (C-Xyloside) and its role in glycosaminoglycan biosynthesis. Eur J Dermatol. 2011;21 (3):359-370. doi:10.1684/ejd.2011.1340

130. Muto J, Naidu NN, Yamasaki K, et al. Exogenous addition of a $\mathrm{C}$-xylopyranoside derivative stimulates keratinocyte dermatan sulfate synthesis and promotes migration. PLoS One. 2011;6 (10):e25480. doi:10.1371/journal.pone.0025480

131. Radek KA, Taylor KR, Gallo RL. FGF-10 and specific structural elements of dermatan sulfate size and sulfation promote maximal keratinocyte migration and cellular proliferation. Wound Repair Regen. 2009;17(1):118-126. doi:10.1111/j.1524-475X.2008.00449.x

132. Sok J, Pineau N, Dalko-Csiba M, et al. Improvement of the dermal epidermal junction in human reconstructed skin by a new c-xylopyranoside derivative. Eur J Dermatol. 2008;18 (3):297-302.

133. Burgeson RE. Type VII collagen, anchoring fibrils, and epidermolysis bullosa. J Invest Dermatol. 1993;101(3):252-255. doi:10.1111/1523-1747.ep12365129

134. Dawson RA, Goberdhan NJ, Freedlander E, et al. Influence of extracellular matrix proteins on human keratinocyte attachment, proliferation and transfer to a dermal wound model. Burns. 1996;22(2):93-100. doi:10.1016/0305-4179(95)00092-5

135. Pineau N, Bernerd F, Cavezza A, et al. A new C-xylopyranoside derivative induces skin expression of glycosaminoglycans and heparan sulphate proteoglycans. Eur J Dermatol. 2008;18 (1):36-40.

136. McMillan JR, Akiyama M, Shimizu H. Epidermal basement membrane zone components: ultrastructural distribution and molecular interactions. J Dermatol Sci. 2003;31(3):169-177. doi:10.1016/S0923-1811(03)00045-8

137. Tsunenaga M, Adachi E, Amano S, et al. Laminin 5 can promote assembly of the lamina densa in the skin equivalent model. Matrix Biol. 1998;17(8-9):603-613. doi:10.1016/S0945-053X (98)90111-1

138. Draelos ZD, Yatskayer M, Raab S, et al. An evaluation of the effect of a topical product containing $\mathrm{C}$-xyloside and blueberry extract on the appearance of type II diabetic skin. J Cosmet Dermatol. 2009;8 (2):147-151. doi:10.1111/j.1473-2165.2009.00428.x

139. Raab S, Yatskayer M, Lynch S, et al. Clinical evaluation of a multi-modal facial serum that addresses hyaluronic acid levels in skin. J Drugs Dermatol. 2017;16(9):884-890.

140. Bouloc A, Roo E, Moga A, et al. A compensating skin care complex containing pro-xylane in menopausal women: results from a multicentre, evaluator-blinded, randomized study. Acta Derm Venereol. 2017;97(4):541-542. doi:10.2340/00015555-2572

141. Meyer LJ, Stern R. Age-dependent changes of hyaluronan in human skin. $J$ Invest Dermatol. 1994;102(3):385-389. doi:10.1111/1523-1747.ep12371800

142. Shunsuke Iriyama KU, Tsunenaga M, Adachi E, Amano S. The functional role of basement membrane heparan sulfate in photo-aging. J Soc Cosmet Chem Japan. 2014;48(1):5.

143. Knott A, Reuschlein K, Lucius R, et al. Deregulation of versican and elastin binding protein in solar elastosis. Biogerontology. 2009;10(2):181-190. doi:10.1007/s10522-008-9165-3

144. Hasegawa K, Yoneda M, Kuwabara H, et al. Versican, a major hyaluronan-binding component in the dermis, loses its hyaluronan-binding ability in solar elastosis. J Invest Dermatol. 2007;127(7):1657-1663. doi:10.1038/sj.jid.5700754

145. Vuillermoz B, Wegrowski Y, Contet-Audonneau JL, et al. Influence of aging on glycosaminoglycans and small leucine-rich proteoglycans production by skin fibroblasts. Mol Cell Biochem. 2005;277(12):63-72. doi:10.1007/s11010-005-5073-x
146. Jin CL, Oh JH, Han M, et al. UV irradiation-induced production of monoglycosylated biglycan through downregulation of xylosyltransferase 1 in cultured human dermal fibroblasts. $J$ Dermatol Sci. 2015;79(1):20-29. doi:10.1016/j.jdermsci.2015.03.018

147. Jung JY, Oh JH, Kim YK, et al. Acute UV irradiation increases heparan sulfate proteoglycan levels in human skin. J Korean Med Sci. 2012;27(3):300-306. doi:10.3346/jkms.2012.27.3.300

148. Michelet JF, Olive C, Rieux E, et al. The anti-ageing potential of a new jasmonic acid derivative (LR2412): in vitro evaluation using reconstructed epidermis episkin ${ }^{\mathrm{TM}}$. Exp Dermatol. 2012;21 (5):398-400. doi:10.1111/j.1600-0625.2012.01480.x

149. Tran C, Michelet JF, Simonetti L, et al. In vitro and in vivo studies with tetra-hydro-jasmonic acid (LR2412) reveal its potential to correct signs of skin ageing. J Eur Acad Dermatol Venereol. 2014;28(4):415-423. doi:10.1111/jdv.12113

150. Farwick M, Grether-Beck S, Marini A, et al. Bioactive tetrapeptide GEKG boosts extracellular matrix formation: in vitro and in vivo molecular and clinical proof. Exp Dermatol. 2011;20 (7):602-604. doi:10.1111/j.1600-0625.2011.01307.x

151. Chaudhuri RK, Bojanowski K. Improvement of hydration and epidermal barrier function in human skin by a novel compound isosorbide dicaprylate. Int J Cosmet Sci. 2017;39(5):518-526. doi:10.1111/ics. 12405

152. Bissett DL, Robinson LR, Raleigh PS, et al. Reduction in the appearance of facial hyperpigmentation by topical $\mathrm{N}$-acetyl glucosamine. J Cosmet Dermatol. 2007;6(1):20-26. doi:10.1111/ j.1473-2165.2007.00295.x

153. Tu CX, Zhang RX, Zhang XJ, et al. Exogenous $\mathrm{N}$-acetylglucosamine increases hyaluronan production in cultured human dermal fibroblasts. Arch Dermatol Res. 2009;301 (7):549-551. doi:10.1007/s00403-009-0932-z

154. Avantaggiato A, Bertuzzi G, Vitiello U, et al. Role of antioxidants in dermal aging: an in vitro study by q-RT-PCR. Aesthetic Plast Surg. 2014;38(5):1011-1016. doi:10.1007/s00266-014-0380-9

155. Nakai K, Yoneda K, Murakami Y, et al. Effects of topical $\mathrm{N}$-acetylcysteine on skin hydration/transepidermal water loss in healthy volunteers and atopic dermatitis patients. Ann Dermatol. 2015;27(4):450-451. doi:10.5021/ad.2015.27.4.450

156. Hamalainen L, Kärkkäinen E, Takabe P, et al. Hyaluronan metabolism enhanced during epidermal differentiation is suppressed by vitamin $\mathrm{C}$. Br J Dermatol. 2018;179(3):651-661. doi:10.1111/bjd.16423

157. Humbert PG, Haftek M, Creidi P, et al. Topical ascorbic acid on photoaged skin. Clinical, topographical and ultrastructural evaluation: double-blind study vs. placebo. Exp Dermatol. 2003;12 (3):237-244. doi:10.1034/j.1600-0625.2003.00008.x

158. Raschke T, Koop U, Düsing HJ, et al. Topical activity of ascorbic acid: from in vitro optimization to in vivo efficacy. Skin Pharmacol Physiol. 2004;17(4):200-206. doi:10.1159/000078824

159. Zasada M, Budzisz E. Retinoids: active molecules influencing skin structure formation in cosmetic and dermatological treatments. Postepy Dermatol Alergol. 2019;36(4):392-397. doi:10.5114/ada.2019.87443

160. Ud-Din S, Foden P, Mazhari M, et al. A double-blind, randomized trial shows the role of zonal priming and direct topical application of epigallocatechin-3-gallate in the modulation of cutaneous scarring in human skin. J Invest Dermatol. 2019;139(8):1680-1690. doi:10.1016/j.jid.2019.01.030

161. Yoshida H, Yamazaki K, Komiya A, et al. Inhibitory effects of Sanguisorba officinalis root extract on HYBID (KIAA1199)-mediated hyaluronan degradation and skin wrinkling. Int J Cosmet Sci. 2019;41(1):12-20. doi:10.1111/ics.12505

162. Narurkar VA, Fabi SG, Bucay VW, et al. Rejuvenating hydrator: restoring epidermal hyaluronic acid homeostasis with instant benefits. J Drugs Dermatol. 2016;15(1 Suppl 2):s24-s37. 
163. McDaniel DH, Dover JS, Wortzman M, et al. In vitro and in vivo evaluation of a moisture treatment cream containing three critical elements of natural skin moisturization. J Cosmet Dermatol. 2020;19(5):1121-1128. doi:10.1111/ jocd.13359
164. Henriet E, Jager S, Tran C, et al. A jasmonic acid derivative improves skin healing and induces changes in proteoglycan expression and glycosaminoglycan structure. Biochim Biophys Acta Gen Subj. 2017;(1861(9):2250-2260. doi:10.1016/j. bbagen.2017.06.006

\section{Publish your work in this journal}

Clinical, Cosmetic and Investigational Dermatology is an international, peer-reviewed, open access, online journal that focuses on the latest clinical and experimental research in all aspects of skin disease and cosmetic interventions. This journal is indexed on CAS.
The manuscript management system is completely online and includes a very quick and fair peer-review system, which is all easy to use. Visit http://www.dovepress.com/testimonials.php to read real quotes from published authors. 